\title{
Shock Wave Propagation Characteristics of Cylindrical Charge and Its Aspect Ratio Effects on the Damage of RC Slabs
}

\author{
Xiaohua Zhao $\mathbb{D}^{1,2,3}$ Gaohui Wang ${ }^{1},{ }^{4}$ Hongyuan Fang, ${ }^{1,2}$ Yong Fan $\left(\mathbb{D},{ }^{3}\right.$ \\ and Xueming Du iD ${ }^{1,2}$ \\ ${ }^{1}$ School of Water Conservancy Engineering, Zhengzhou University, Zhengzhou 450001, China \\ ${ }^{2}$ National Local Joint Engineering Laboratory of Major Infrastructure Testing and Rehabilitation Technology, \\ Zhengzhou 450001, China \\ ${ }^{3}$ Hubei Key Laboratory of Construction and Management in Hydropower Engineering, China Three Gorges University, \\ Yichang 443002, China \\ ${ }^{4}$ State Key Laboratory of Water Resources and Hydropower Engineering Science, Wuhan University, Wuhan 430072, China \\ Correspondence should be addressed to Yong Fan; yfan@ctgu.edu.cn
}

Received 24 April 2021; Accepted 19 July 2021; Published 30 July 2021

Academic Editor: José António Correia

Copyright $(2021$ Xiaohua Zhao et al. This is an open access article distributed under the Creative Commons Attribution License, which permits unrestricted use, distribution, and reproduction in any medium, provided the original work is properly cited.

Antiknock research of reinforced concrete (RC) slabs is often carried out with spherical or nearly spherical explosives, although many explosives used in engineering and military are cylinder shaped. It is known that the shock wave caused by cylindrical explosives varies in different directions, which is quite different from the spherical charge. In this paper, the shock wave propagation characteristics of spherical and cylindrical explosives with different aspect ratios are compared and analyzed. The $2 \mathrm{D}$ numerical results show the peak overpressure from the cylindrical explosive is significantly affected by the $L / D$ (length/diameter) ratio. Subsequently, the damage features of RC slabs under spherical and cylindrical explosives with a certain $L / D$ ratio are investigated through an explosion experiment. Finally, the influence of the $L / D$ ratio on the dynamic response of RC slabs under cylindrical explosives is studied by the fully coupled Euler-Lagrange method. The accuracy and reliability of the coupled model are verified by comparing the numerical with experimental results. Based on the experimental and numerical studies, it can be concluded that the explosive shape directly determines the shape of upper surface crater damage, and the spall damage area of RC slabs becomes larger as the $L / D$ increases. For the $L / D$ increases to a certain value, the cylindrical explosive will induce larger spall damage than that induced by spherical charge with the same amount of explosives. Hence, the effect of the cylindrical charge should be considered in the antiknock design of the RC structure.

\section{Introduction}

The design manuals for blast-resistant design are largely based on data of spherical free-air bursts [1]. For example, the UFC 3-340-02 [2], TM 5-1300 [3], and the ASCE/EI 5911 [4] are largely based on the test results of spherical explosives, ignoring the influence of explosive shape on the characteristics of the shock wave. However, most military explosives and packaging of rock emulsion explosives are cylindrical, such as aerial bomb and 2\# rock emulsion explosive, as shown in Figure 1.
For spherical explosives, the shock wave propagation characteristics are consistent in all directions due to its symmetry. However, for the cylindrical explosive, the shock wave radiates from both ends and sides of the cylinder and reflects off each other, which makes the pressure histories exhibit multiple shocks $[5,6]$. Moreover, the cylindrical explosive geometry has a significant effect on blasting shock waves as compared to spherical explosives [7, 8]. And the energy distribution in the axial and radial directions of the cylinder is directly affected by the $L / D$ ratio of the cylindrical explosive $[9,10]$. The formulas and charts for calculating the 


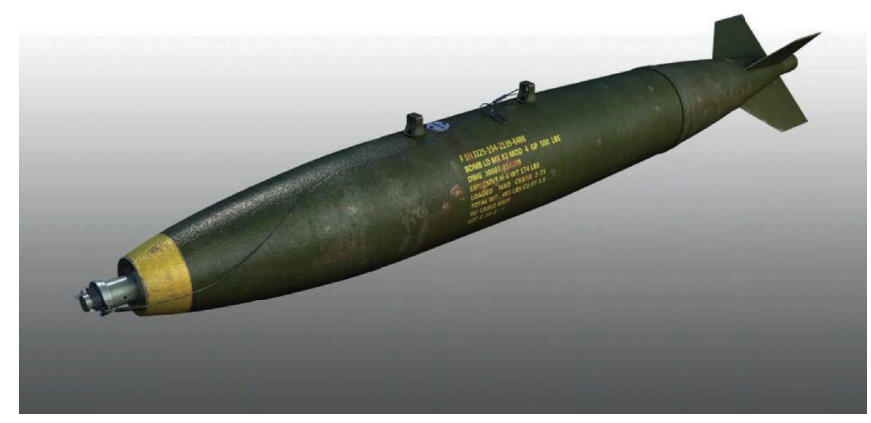

(a)

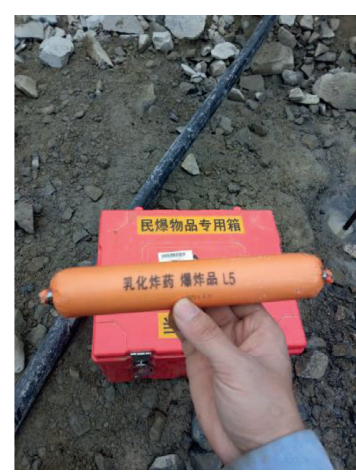

(b)

FIGURE 1: Shapes of the military charges and rock emulsion explosive in construction site. (a) Aerial bomb. (b) Rock emulsion explosive.

peak value of shock wave overpressure of cylindrical explosives have been given $[11,12]$. However, although some researchers $[6,13,14]$ have found that the $L / D$ ratio has a great influence on the blast wave induced by cylindrical explosives, few equations have been given to explain this effect. One equation [15] does take into account the $L / D$ to predict the shock wave overpressure induced by cylindrical charges, but this formula is only applicable to the axial direction of cylindrical explosives. To predict peak overpressure at any angle around the explosive, Plooster [16] gave two formulas for explosives shaped in cylindrical with $L / D \geq 1$ and $L / D<1$. But these equations are explosive dependent and very complex with multiple parameters for different types of explosives. Hence, the shock wave histories and peak overpressure equation of cylindrical explosives with different $L / D$ ratios are still needed for further research.

At present, researches on the dynamic responses and damage characteristics of concrete slabs subjected to contact blasting loads mainly focused on cylindrical explosives with $L / D$ being $1 / 1$ [17-20] or $1 / 2$ [21-23], which are nearly spherical explosives [24]. However, for the cylindrical explosive with a certain $L / D$, a significant difference in damage features was observed when the orientation of the explosive with respect to the slab was different [25]. As the principal engineering structure, RC slab has been widely used in the fields of hydropower and civil engineering. Moreover, blasting loads can cause serious damage and failure to the reinforced concrete structures. Under contact blasting loads, the reinforced concrete will undergo upper surface crater damage, overall large deformation, bottom surface spall damage [26], and even punching damage. With the increasing frequency of terrorist attacks in recent years, more and more researchers pay attention to the damage features of RC slabs under blasting loads. Given that there have been few published works on the damage modes of RC slabs subjected to cylindrical explosives, numerical simulation analysis and explosion tests should be carried out.

In this study, the pressure contours and histories induced by cylindrical explosives are numerically analyzed in a two-dimensional (2D) air domain. The influence of $L / D$ ratio on peak overpressures induced by cylindrical explosives is comparatively investigated with spherical explosives. Then, the damage features of RC slabs under spherical and cylindrical explosives are investigated through a contact explosion experiment. Finally, a 3D fully coupled model is developed and validated against the blasting testing results. Using the verified numerical model, the damage features and dynamic response of the RC slab under spherical and cylindrical explosives with different $L / D$ ratios are compared and discussed.

\section{Effects of Aspect Ratio on the Shock Wave Propagation Characteristics Induced by the Cylindrical Explosive}

In this section, a two-dimensional model is employed to investigate the shock wave propagation characteristics and peak overpressure induced by cylindrical explosives with different $L / D$ ratios and compared with spherical explosives.

2.1. Geometry Model. In order to analyze the influence of aspect ratio on the shock wave propagation induced by the cylindrical explosive, a free field air explosion is simulated based on the 2D model. One spherical and five cylindrical explosives are used with the weight of $1.5 \mathrm{~kg}$; the $L / D$ ratios of the cylindrical explosives are 0.2, 0.6, 1.0, 2.0, and 5.0, respectively, as shown in Figure 2. The initiation point is set in the center of the explosive in all of the charges. The explosive is modeled by the central symmetric, and the symmetric axis is the axis of the cylindrical explosive, as shown in Figure 2.

Studies have shown that the exact value of the blast wave overpressure at a small standoff distance is difficult to measure, from either numerical simulations or blasting tests [27]. Furthermore, the maximum scaled distance that could cause damage to RC structures is taken to be $1.6 \mathrm{~m} / \mathrm{kg}^{1 / 3}$. Hence, the range of the scaled distance for shock wave analysis in the present paper is limited to be from 0.4 to $1.6 \mathrm{~m} / \mathrm{kg}^{1 / 3}$. The overpressure from the explosive is monitored by 21 target points, as shown in Figure 2. Among them, target points 1-7 are all arranged along the radial direction of the cylindrical explosive, target points 8-14 are all arranged in the $45^{\circ}$ direction, and target points 15-21 are all 


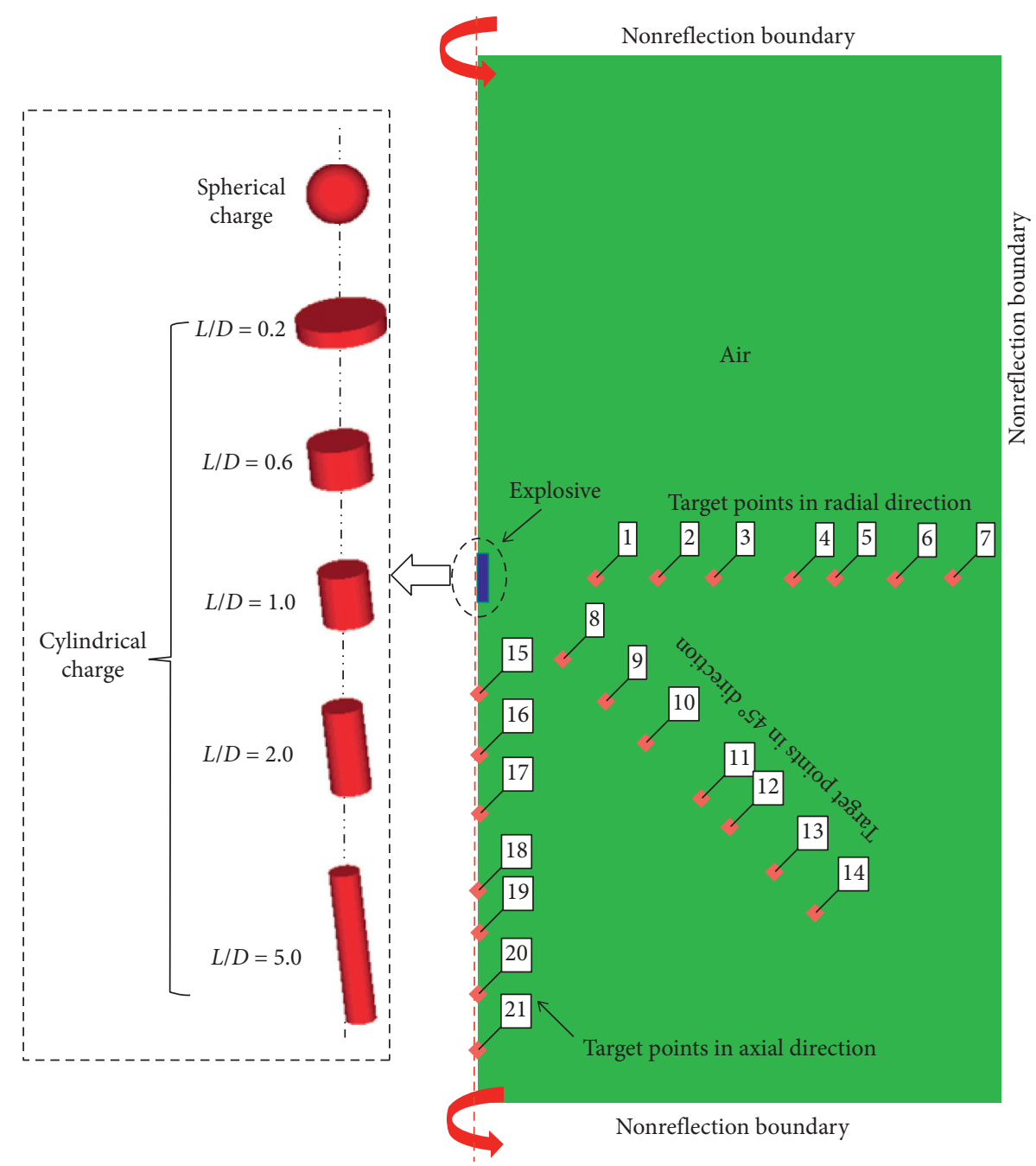

Figure 2: Geometry models of the cylindrical and spherical explosive simulation.

arranged in the axial direction. The termination time is selected to be $2 \mathrm{~ms}$, in which the shock wave has passed the farthest measuring point. Both of the TNT and air are modeled by the Euler mesh; in this mesh the space grid is fixed but the materials can flow free through it. The nonreflection boundary is applied at all the boundaries of the air to eliminate the impact of shock wave reflection on the calculation results.

2.2. Material Models for Air and Explosive. The JWL (JonesWilkins-Lee) EOS is widely used to model the explosive, such as TNT and rock emulsion explosive, in numerical studies [28]. To compare the numerical results with Kinney Formula and blasting test results, TNT and rock emulsion explosive are used in this section and Section 4, respectively. Referring to the research by Sanchidrian et al. [29], the parameters of rock emulsion explosives used in this paper are given in Table 1. The parameters for TNT are available in AUTODYN, which have been verified by comparing with dynamic tests.

The ideal gas expression of state is used to model the air material in this paper, and the pressure is related to the energy by
TABLE 1: Material parameters for rock emulsion explosive.

\begin{tabular}{lc}
\hline Parameters & Rock emulsion explosive \\
\hline$\rho\left(\mathrm{g} / \mathrm{cm}^{3}\right)$ & 1.05 \\
$D(\mathrm{~m} / \mathrm{s})$ & 3850 \\
$A(\mathrm{GPa})$ & 209.7 \\
$B(\mathrm{GPa})$ & 3.50 \\
$P_{C J}(\mathrm{GPa})$ & 3.7 \\
$R_{1}$ & 5.76 \\
$R_{2}$ & 1.29 \\
$\omega$ & 0.39 \\
$e_{0}(\mathrm{GPa})$ & 4.20 \\
\hline
\end{tabular}

$$
P=(\gamma-1) \rho e,
$$

where constant-pressure to constant-volume specific heat ratio $\gamma=1.4$; specific internal energy $e=2.068 \times 10^{5} \mathrm{~kJ} / \mathrm{kg}$; $\rho=\rho_{c} / \rho_{0}, \rho_{c}$ represents the current density, and initial density $\rho_{0=1} 1.225 \mathrm{~kg} / \mathrm{m}^{3}[28]$.

2.3. Influence of the Cylindrical Explosives on Shock Wave Propagation Characteristics in Air. The contours of the shock wave pressure for both the spherical and cylindrical 
explosives with different $L / D$ ratios (i.e., $L / D=0.2,0.6,1.0$, 2.0 , and 5.0 ) at $t=0.5 \mathrm{~ms}, t=1.0 \mathrm{~ms}$, and $t=1.5 \mathrm{~ms}$ are shown in Figures 3-5. These graphs show the qualitative information of the shock wave pressure and the overall shape of the shock wave, enabling comparisons of the spherical explosive with the cylindrical explosives.

Figures 3-5 show that the shock wave induced by the spherical explosive is the same in all directions. However, for the cylindrical explosives, the $L / D$ ratio has a significant impact on the overall shape of the shock wave and the peak pressure. The peak shock wave pressures from the cylindrical explosives are greater than those from the spherical explosive. Moreover, the shock wave is concentrated more in the axial direction for the cylindrical explosives with $L / D=0.2$ and $L / D=0.6$. As the aspect ratio increases, more blasting energy is concentrated in the radial direction. When the $L / D$ ratio increases to 2.0 , the shock wave propagating along the radial direction is significantly greater than that propagating along the axial direction, as shown in Figures 3-5.

One prominent feature in the fringe plot of cylindrical charge is the bridge wave (Figure 3 ). This is because after the cylindrical explosive is detonated, the spherical waves radiate out from the sides of the cylinder explosive as well as the ends of the cylinder explosive, propagating along the axial and radial directions. In the process of propagation and interaction of these blast waves, bridge waves are generated in the area of axial and radial intersection. With the increase of the propagation distance of the shock wave, the bridge wave grows in size and the overall shape of the shock wave gradually becomes a circle, as shown in Figure 5.

To investigate the influence of the $L / D$ ratio on the blasting pressure propagation characteristics, the pressure histories of target 5, target 12 , and target 19 are given in Figure 6. It should be noted that target 5 is arranged in the radial direction, target 12 is arranged in $45^{\circ}$ direction, target 19 is arranged in the axial direction (Figure 2).

As can be seen from Figure 6, the shock waves from cylindrical explosives with different $L / D$ ratios are all characterized by a sudden pressure rise to the peak value at the shock front and followed by a quasi-exponential decrease back to ambient value. The rising and amplitude characteristics of the shock wave are consistent with those from spherical explosives as shown in Figure 6. However, the peak value of shock waves and the arrival time of the peak pressure from spherical and cylindrical explosives are quite different. The shock wave histories in radial direction decay more rapidly as the $L / D$ ratio increases, as shown in Figure 6(a). Opposite to the radial direction, the shock wave histories in axial direction decay more slowly as the $L / D$ ratio increases, as shown in Figure 6(c). Due to the bridge wave, the $L / D$ ratio of the cylindrical explosives has little influence on the attenuation of the shock wave in the $45^{\circ}$ direction (Figure 6(b)).

The peak overpressure produced by the spherical and cylindrical explosives with different $L / D$ ratios is presented in Figure 7. Figure 7(a) shows the peak overpressure from cylindrical explosive increases with the increases of $L / D$ in the radial direction. At scaled distance $=0.4 \mathrm{~m} / \mathrm{kg}^{1 / 3}$, the cylindrical explosive with $L / D=5.0$ produces a $116 \%$ greater peak overpressure than that induced by the cylindrical explosive with $L / D=0.2$. However, as the scaled distance increases to $1.6 \mathrm{~m} / \mathrm{kg}^{1 / 3}$, the difference of the peak overpressure between cylindrical explosives with different $L / D$ decreases.

For the $45^{\circ}$ direction, the influence of the $L / D$ ratio on the peak overpressure from cylindrical explosives becomes smaller than the radial direction, as shown in Figure 7(b). All of the cylindrical explosives with $L / D$ increases from 0.2 to 5.0 produce peak overpressure smaller than that produced by the spherical charge. When the scaled distance $>1.6 \mathrm{~m} /$ $\mathrm{kg}^{1 / 3}$, the difference of peak overpressure between the spherical and cylindrical charges in the $45^{\circ}$ direction can be ignored.

The peak overpressure produced by the spherical and cylindrical explosives in the axial direction is presented in Figure $7(\mathrm{c})$. The peak overpressure from cylindrical explosives increases with the decrease of the $L / D$ ratio. And at scaled distance $=0.4 \mathrm{~m} / \mathrm{kg}^{1 / 3}$, the cylindrical explosive with $L / D=0.2$ produces a $126 \%$ greater peak overpressure than the cylindrical explosive with $L / D=5.0$. The cylindrical explosive with $L / D>1.0$ produces greater peak overpressure than spherical explosive. At a scaled distance between $0.4 \mathrm{~m} / \mathrm{kg}^{1 / 3}$ and $1.6 \mathrm{~m} / \mathrm{kg}^{1 / 3}$, the cylindrical explosive with $L / D=1.0$ produces nearly the same peak overpressure as the spherical explosive (Figure $7(\mathrm{c})$ ).

Figure 8 presents the arrival time of peak overpressures from spherical and cylindrical explosives to the target points in the three directions. Figure 8(a) shows the shock pressure propagates faster with the increases of $L / D$ ratio in the radial direction. The shock wave arrival time to the scaled distance of $1.6 \mathrm{~m} / \mathrm{kg}^{1 / 3}$ induced by the cylindrical explosive with $L / D=5.0$ is around $0.6 \mathrm{~ms}$, which is faster than the cylindrical explosive with $L / D=0.2$. However, for the axial direction, the shock wave propagates slower with the increases of $L / D$ ratio (Figure $8(\mathrm{c})$ ). And for the propagation time to the scaled distance of $1.6 \mathrm{~m} / \mathrm{kg}^{1 / 3}$, the cylindrical explosive with $L / D=5.0$ is around $1.0 \mathrm{~ms}$ slower than that induced by the cylindrical explosive with $L / D=0.2$. This is because, in the axial direction, the distance traversed by the shock wave increases with the $L / D$ ratio. Hence, for the given scaled distance, the smaller the $L / D$ ratio, the greater the distance traversed by the shock wave in the air. And as is well known, the shock wave travels slower in the air than in the explosive.

For $45^{\circ}$ direction, the difference of the arrival time of peak overpressure between the spherical and cylindrical explosives with different $L / D$ ratios decreases, but it does still exist (Figure $8(\mathrm{~b})$ ). The arrival time of peak overpressure from the spherical explosive is almost the same as that from the cylindrical explosive with $L / D=1.0$, especially in the axial direction, as shown in Figure 8(c). Overall, as the aspect ratio of the cylindrical explosives changed, not only is more blasting energy concentrated in the axial or radial directions, but also the shock wave propagates faster in a specific direction.

The value of peak overpressure is an important parameter in the antiknock design of concrete structures. Hence, it is necessary to produce a simple and convenient 


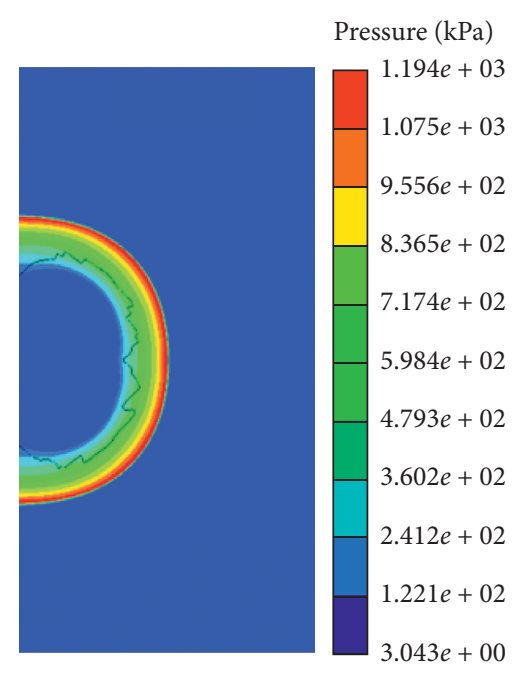

(a)

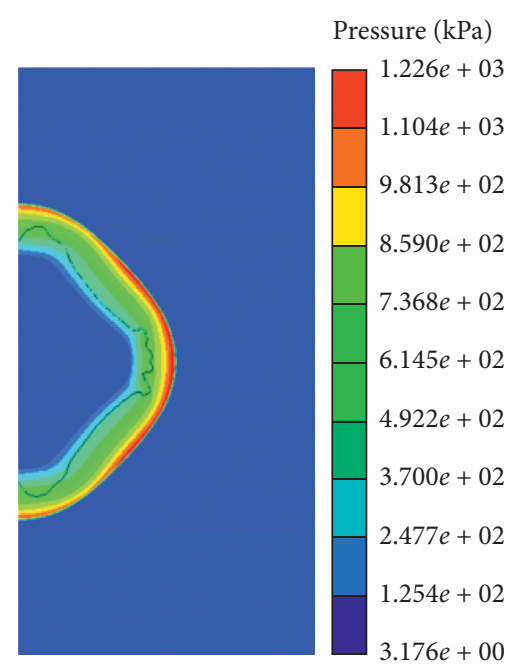

(d)

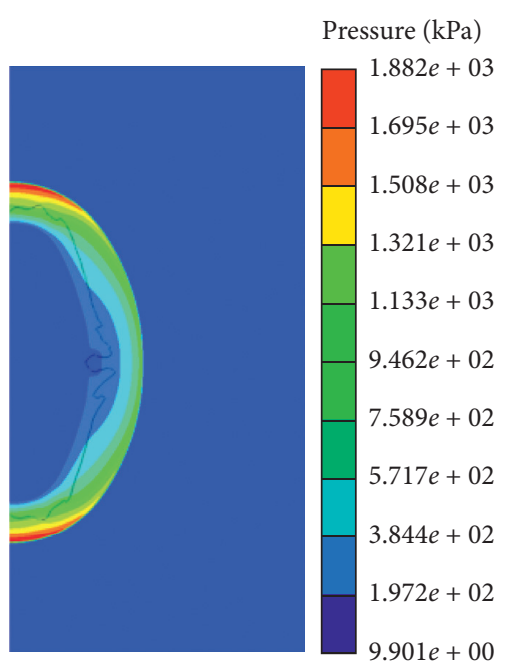

(b)

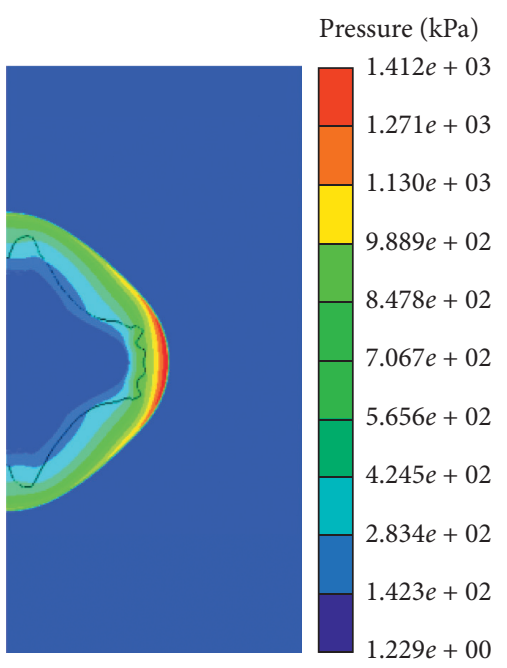

(e)
Pressure $(\mathrm{kPa})$
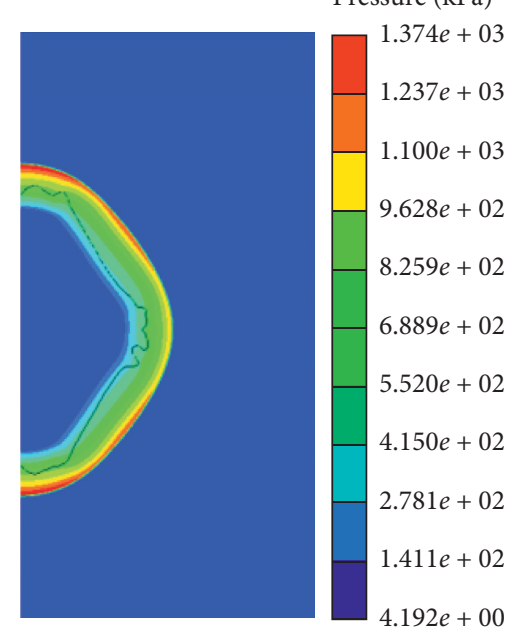

(c)

\section{Pressure $(\mathrm{kPa})$}
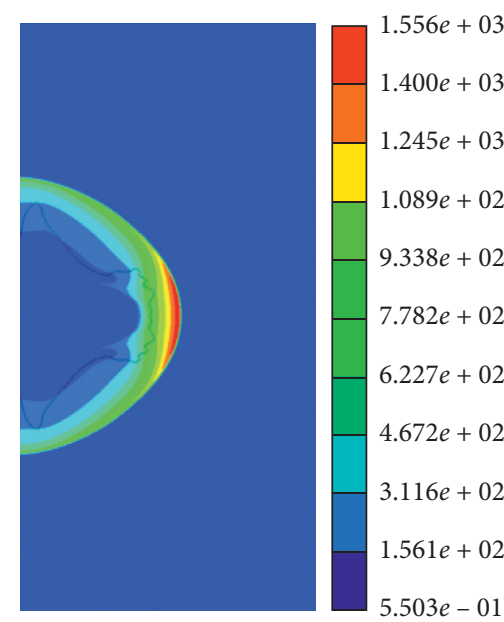

(f)

Figure 3: Pressure contours from spherical charge and cylindrical explosives at $t=0.5 \mathrm{~ms}$. (a) Spherical. (b) Cylindrical, $L / D=0.2$. (c) Cylindrical, $L / D=0.6$. (d) Cylindrical, $L / D=1.0$. (e) Cylindrical, $L / D=2.0$. (f) Cylindrical, $L / D=5.0$.

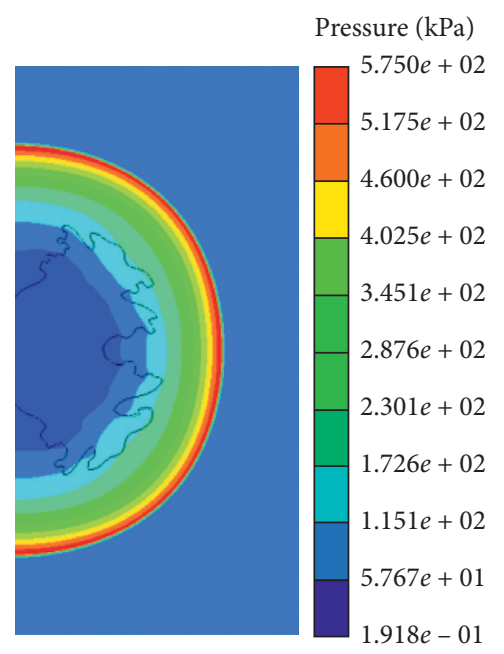

(a)

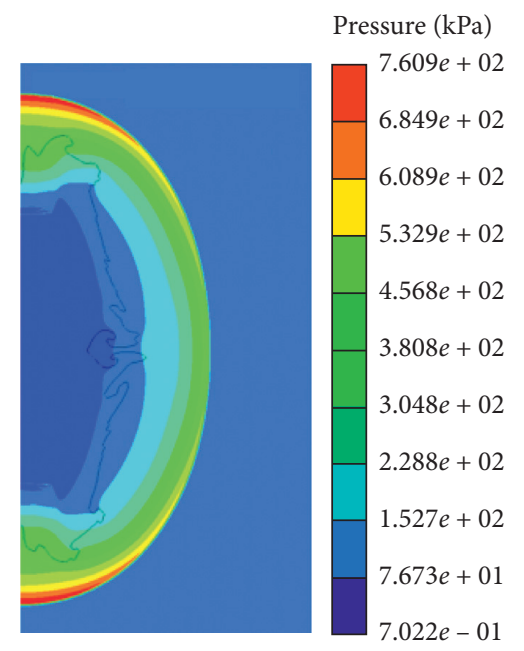

(b)
Pressure $(\mathrm{kPa})$
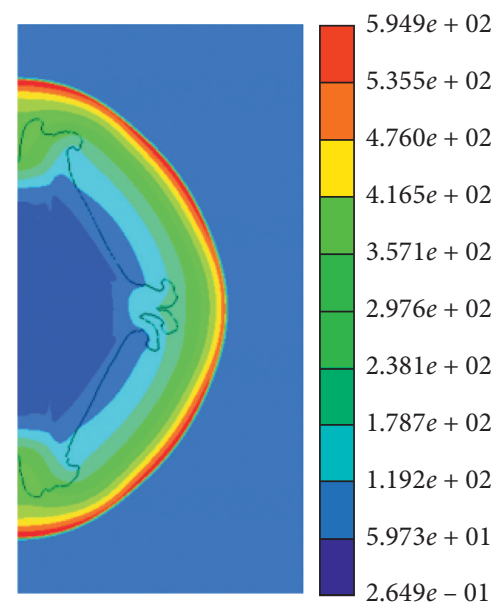

(c)

Figure 4: Continued. 


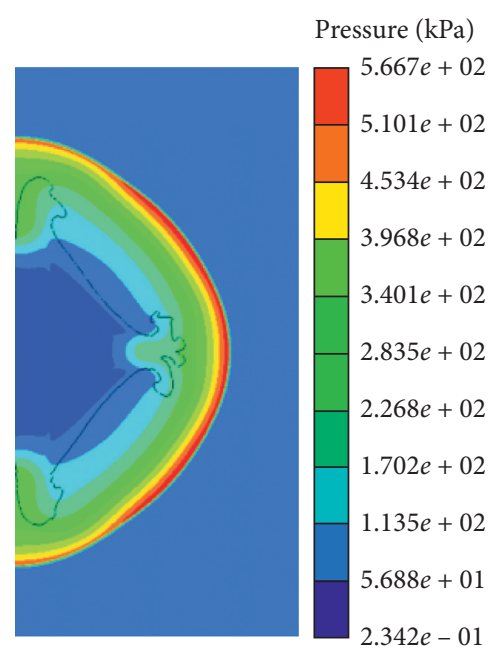

(d)

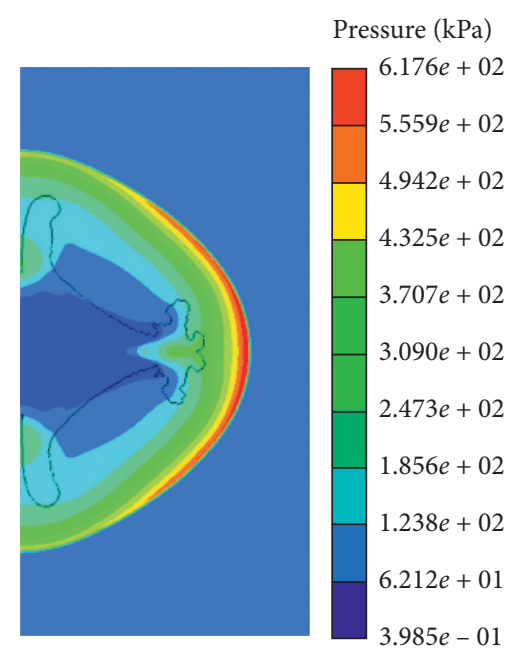

(e)

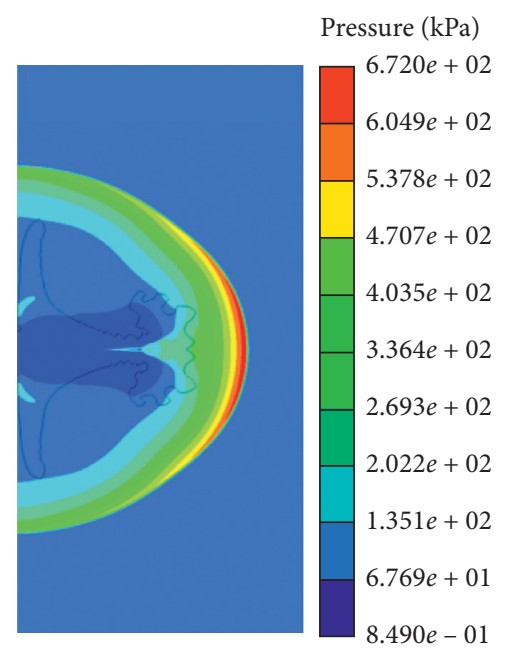

(f)

Figure 4: Pressure contours from spherical charge and cylindrical explosives at $t=1.0 \mathrm{~ms}$. (a) Spherical. (b) Cylindrical, $L / D=0.2$. (c) Cylindrical, $L / D=0.6$. (d) Cylindrical, $L / D=1.0$. (e) Cylindrical, $L / D=2.0$. (f) Cylindrical, $L / D=5.0$.

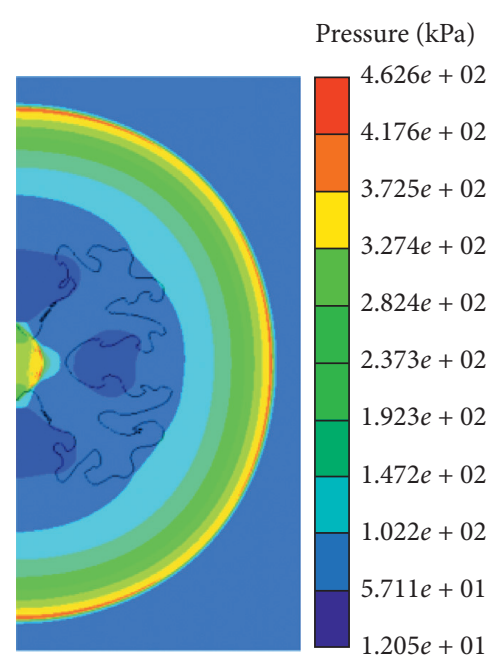

(a)

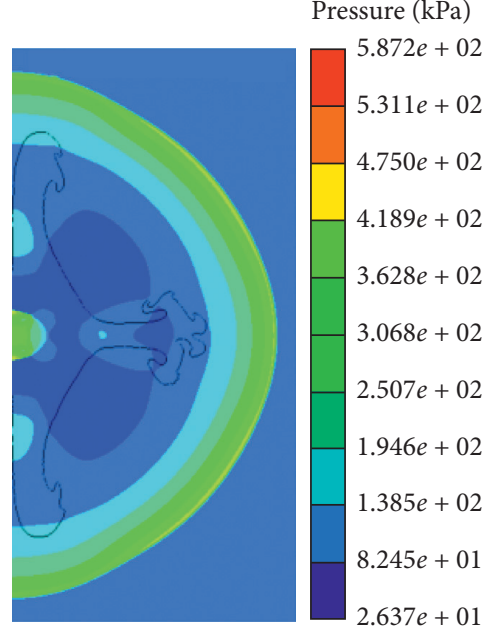

(d)

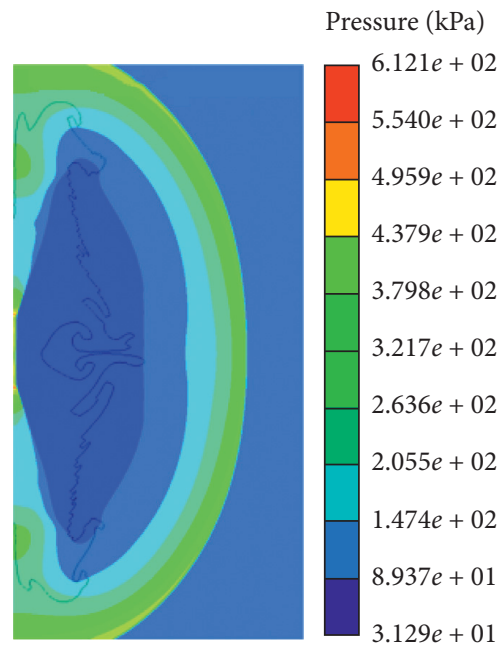

(b)

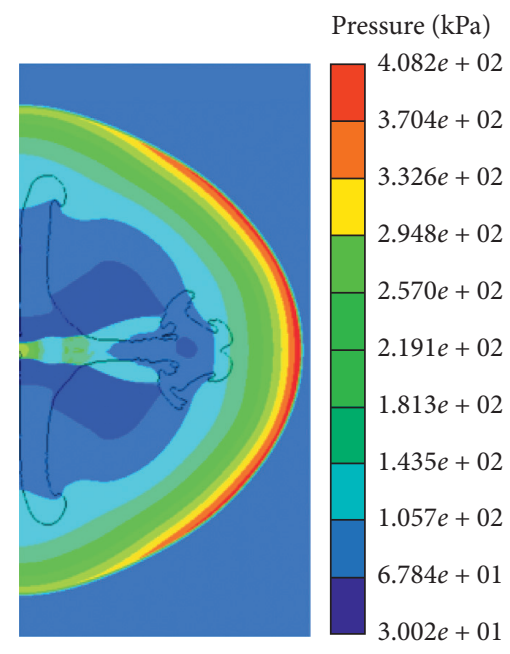

(e)

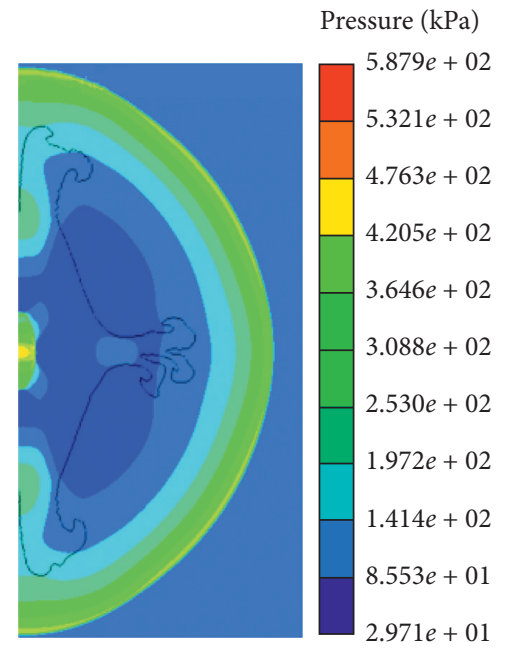

(c)

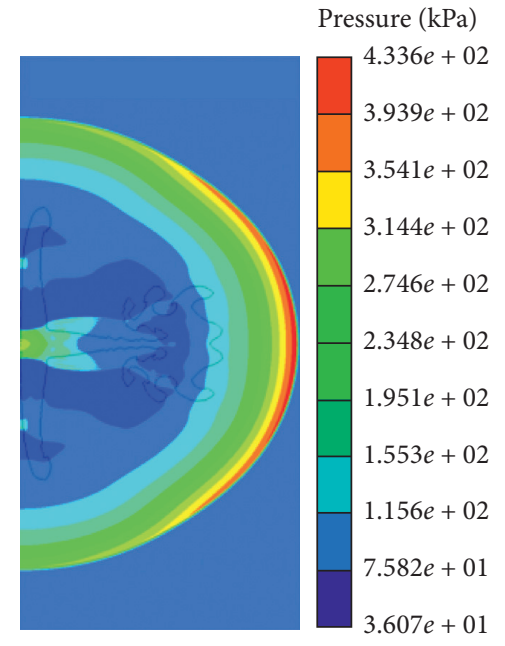

(f)

Figure 5: Pressure contours from spherical charge and cylindrical explosives at $t=1.5 \mathrm{~ms}$. (a) Spherical. (b) Cylindrical, $L / D=0.2$. (c) Cylindrical, $L / D=0.6$. (d) Cylindrical, $L / D=1.0$. (e) Cylindrical, $L / D=2.0$. (f) Cylindrical, $L / D=5.0$. 


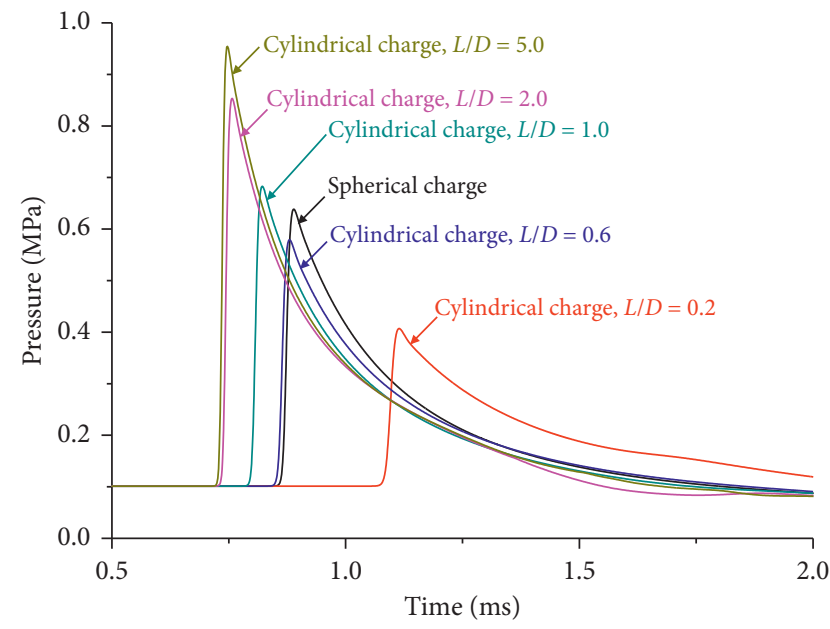

(a)

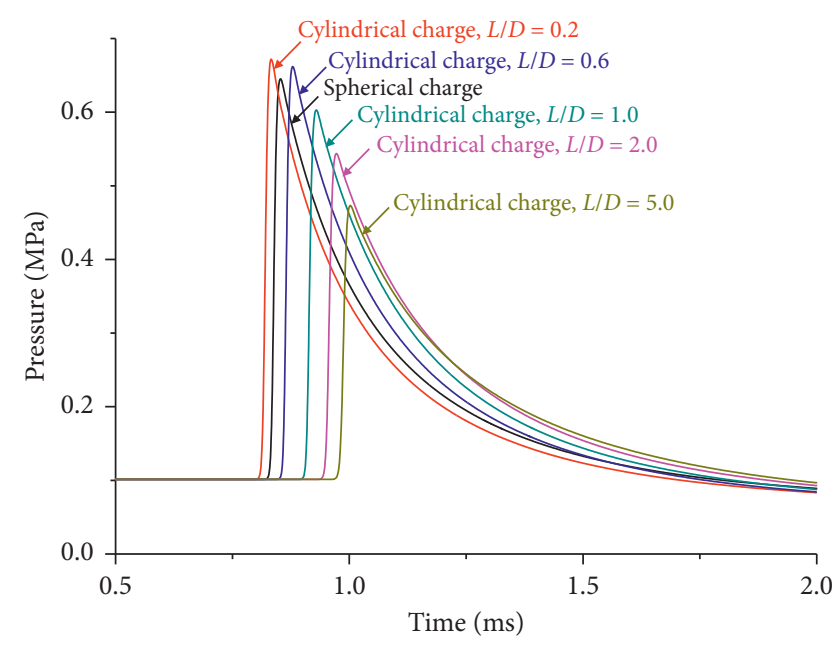

(b)

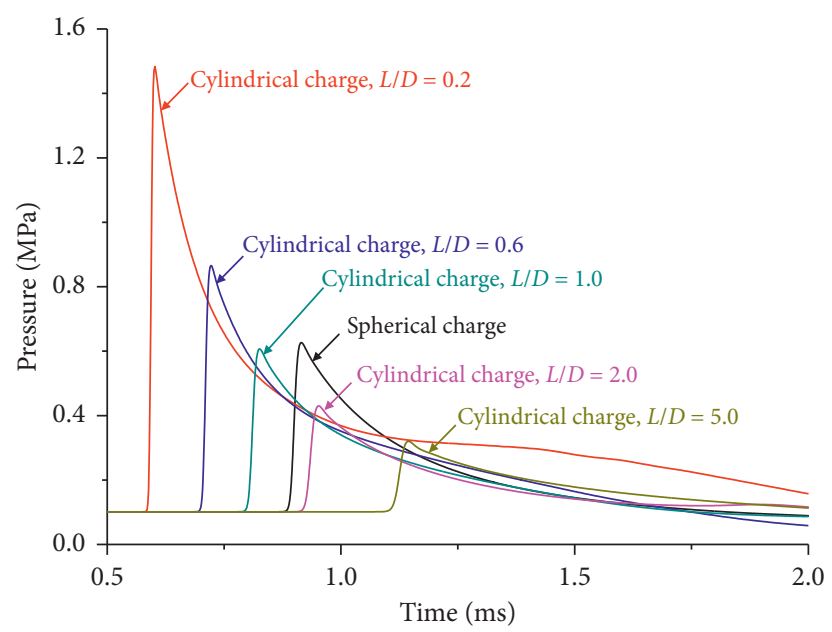

(c)

Figure 6: Comparison of pressure histories from spherical and cylindrical explosives. (a) Target 5 in radial direction. (b) Target 12 in $45^{\circ}$ direction. (c) Target 19 in axial direction.

formula to predict the peak overpressure induced by the cylindrical explosive. The results presented in Figure 7 indicate that the peak overpressures induced by the cylindrical explosives are sensitive to the $L / D$ ratio in the close-in explosion. Based on the Kinney equation [30] and above numerical results, an equation is produced for predicting the peak overpressure induced by a cylindrical explosive in the radial direction, $45^{\circ}$ direction, and axial direction:

$$
\begin{aligned}
& P_{\text {cylinder }}= K * P_{\text {spherical }}, \\
& K= \begin{cases}0.32 \ln \frac{L}{D}+1.05, & \text { radial direction, } \\
-0.09 \ln \frac{L}{D}+0.83, & 45^{\circ} \text { direction, } \\
-0.50 \ln \frac{L}{D}+1.25, & \text { axial direction, }\end{cases}
\end{aligned}
$$

where $P_{\text {cylinder }}$ is the peak overpressure produced by cylindrical explosive, $P_{\text {spherical }}$ is the peak overpressure produced by spherical charge, $K$ is a constant determined by $L / D, L$ is the length of the cylinder, and $D$ represents the diameter of the cylinder.

The peak overpressure from spherical explosives and equation results of cylindrical explosives with different $L / D$ ratios equal to 0.2, 0.6, 1.0, 2.0, and 5.0 are given in Figure 9. For scaled distances $0.6-1.6 \mathrm{~m} / \mathrm{kg}^{1 / 3}$, the equation produces a good prediction of the peak overpressure from all of the three directions.

\section{Experimental Testing of the RC Slabs under Spherical and Cylindrical Explosives}

3.1. Test Setup. In this study, two RC slabs $(500 \mathrm{~mm} \times 500 \mathrm{~mm} \times 60 \mathrm{~mm})$ are tested under contact blasting explosives in free air. The reinforcement diameter of the RC slab is $6 \mathrm{~mm}$, the spacing is $100 \mathrm{~mm}$, and the cover depth is $20 \mathrm{~mm}$ (Figure 10). Young's modulus of the reinforcement steel is $200 \mathrm{GPa}$, and the yield strength of the reinforcement steel is $600 \mathrm{MPa}$. The compressive strength of 


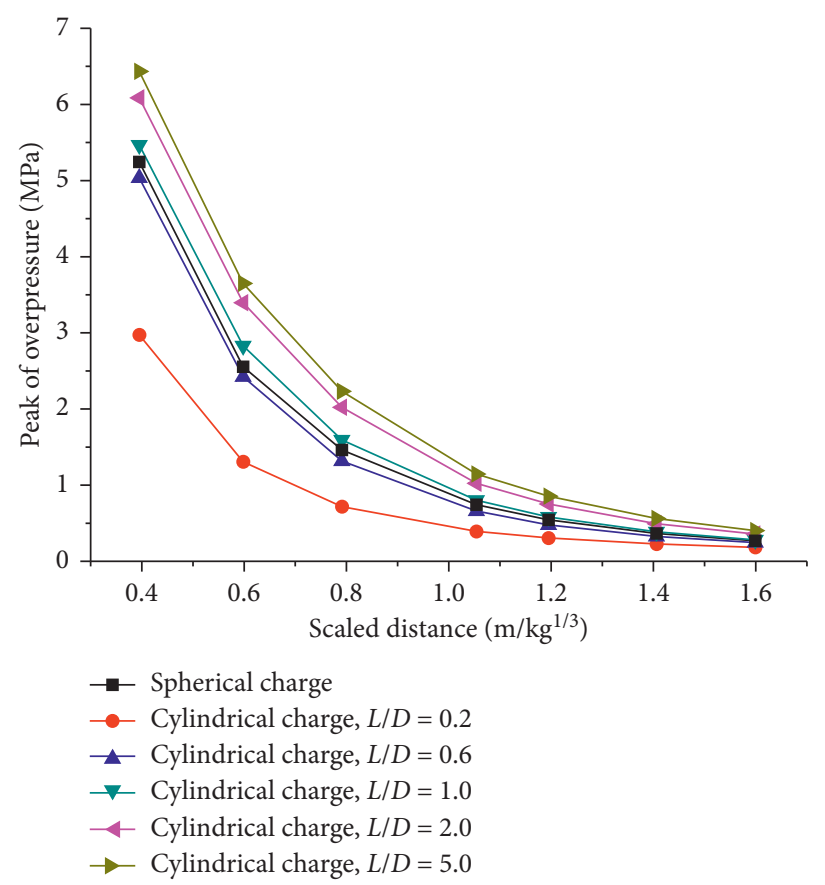

(a)

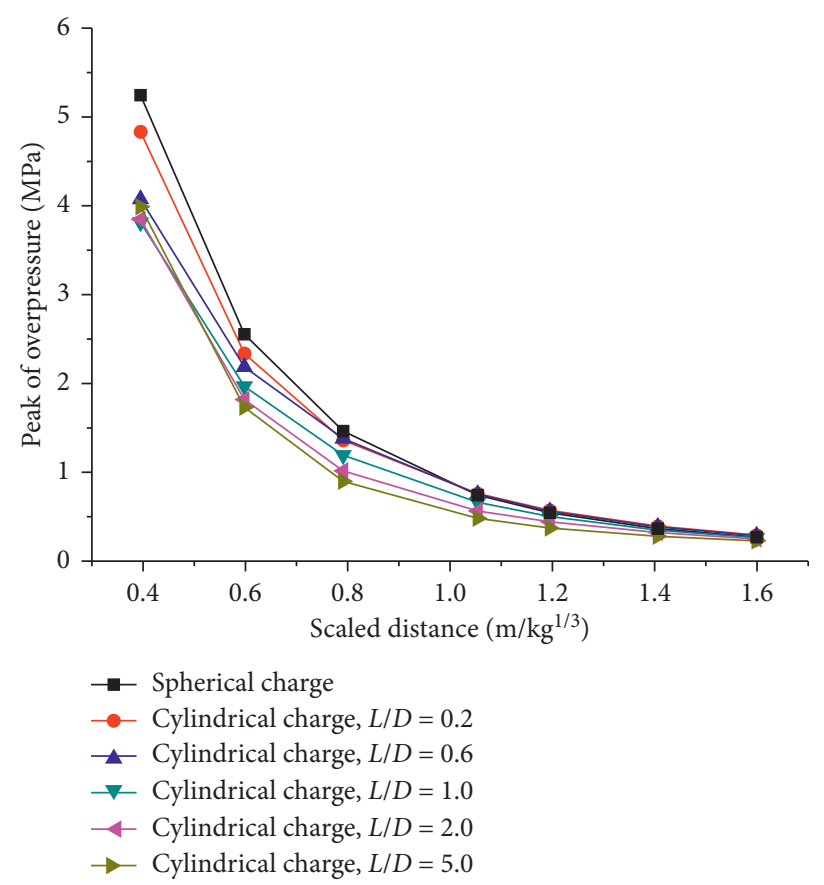

(b)

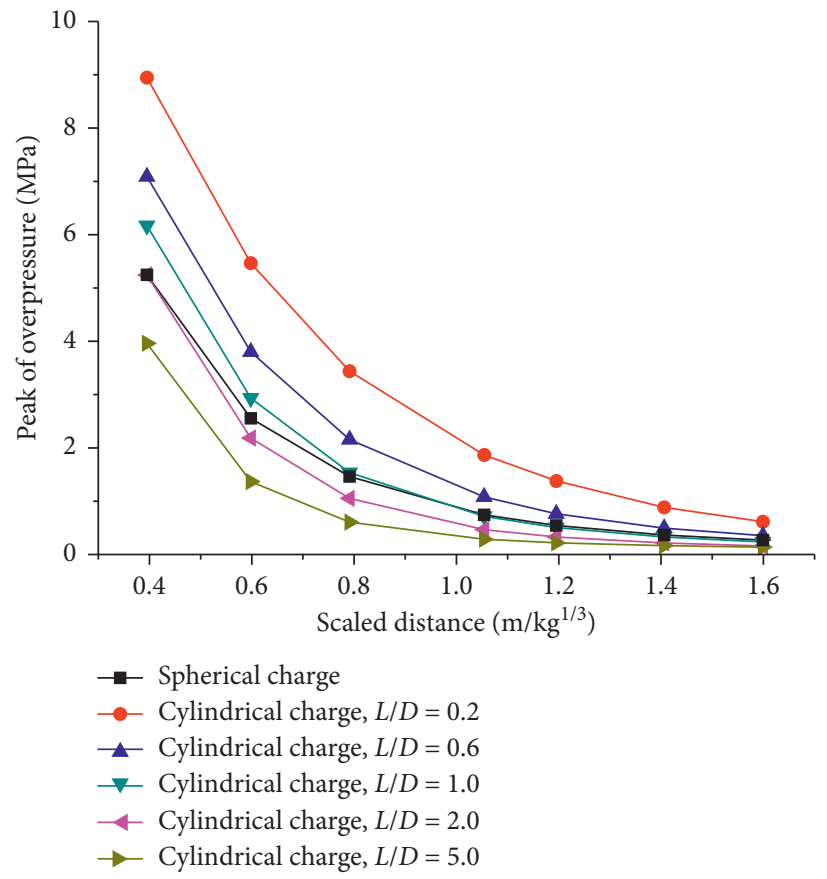

(c)

Figure 7: Comparison of the peak overpressure from spherical and cylindrical explosives. (a) Radial direction. (b) $45^{\circ}$ direction. (c) Axial direction.

the concrete is $39.5 \mathrm{MPa}$. To provide a fixed boundary condition to the slab, a steel frame was welded, and the gap between the slab and the steel frame is filled with triangle steel and a special wedge iron piece (Figure 11).

The explosive type used in the experiment is emulsion explosive; the density and brisance are $1.05 \mathrm{~g} / \mathrm{cm}^{3}$ and $12 \mathrm{~mm}$. In the experiment, $20 \mathrm{~g}$ emulsion explosives in spherical and cylindrical shape with $L / D=4.0$ are placed on the upper surface center of the RC slabs, respectively (Figure 11). The emulsion explosive is detonated by the inserted electric detonator, and the emulsion explosive equivalent of the electric detonator is $1 \mathrm{~g}$ [22].

3.2. Test Results. After the explosion, concrete crater and spall damage are observed under both the spherical and cylindrical explosives, and no flexural damage is observed, as 


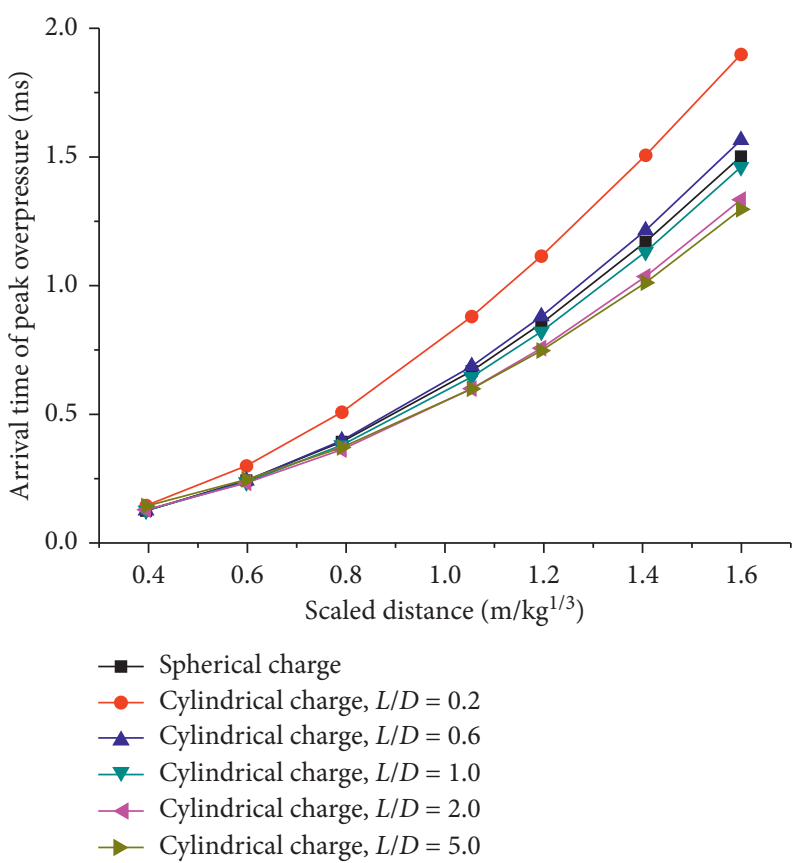

(a)

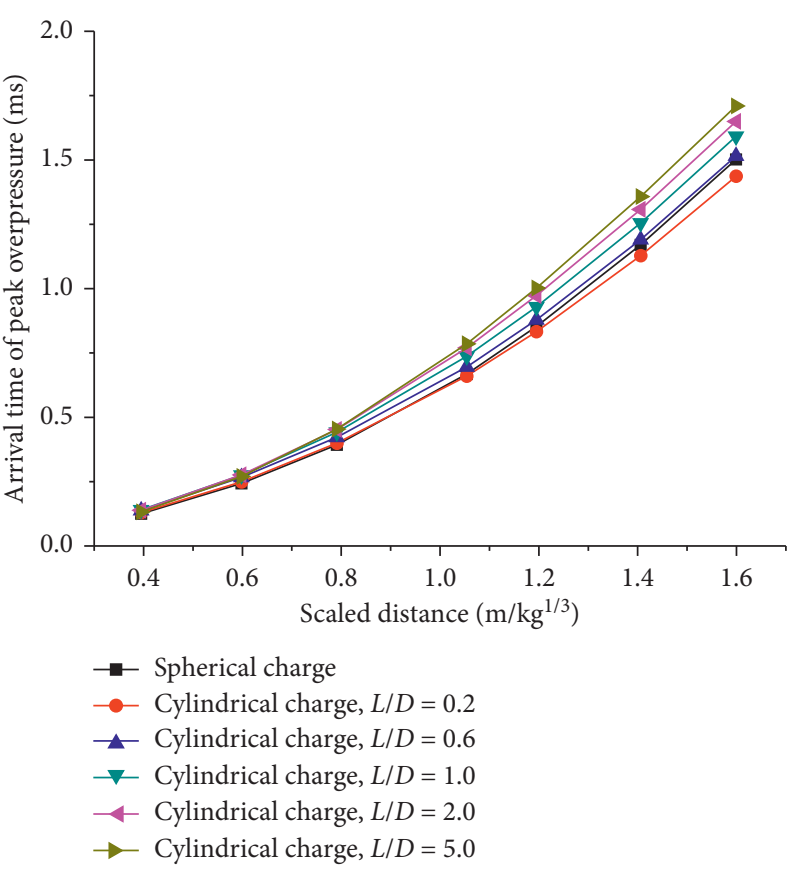

(b)

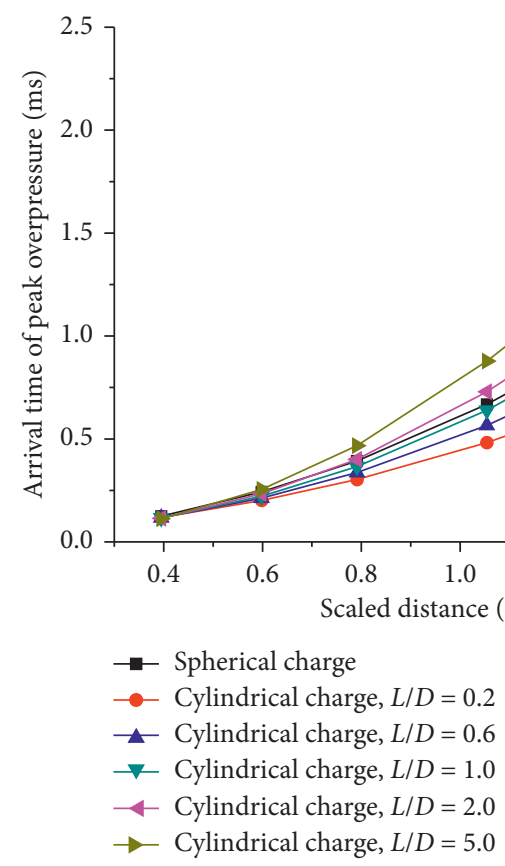

(c)

Figure 8: The arrival time of the peak overpressure. (a) Radial direction. (b) $45^{\circ}$ direction. (c) Axial direction.

shown in Figures 12 and 13. Moreover, no concrete cracking is observed in either of the RC slabs; this is because the reinforcement steels can effectively prevent the cracking of the RC slab and improve the overall antiknock performance of the RC slab.

As shown in Figures 12(a) and 13(a), the shapes of concrete crater damage under spherical and cylindrical explosives are circle and rectangular, respectively, which are keeping the same shape as the explosives. The crater diameter of the RC slab upper surface under spherical explosive is approximately $7 \mathrm{~cm}$. The length of the damage on the upper surface of the slab under cylindrical explosive is approximately $9.5 \mathrm{~cm}$. Figures 12(b) and 13(b) show that both of the RC slabs suffer circle shape spall damage on the bottom surface. The diameters of the spall damage subjected to spherical and cylindrical explosives are $18 \mathrm{~cm}$ and $17 \mathrm{~cm}$, respectively. Moreover, comparing with cylindrical explosive, it is clear that the RC slab suffers deeper spall damage under the spherical explosive. 


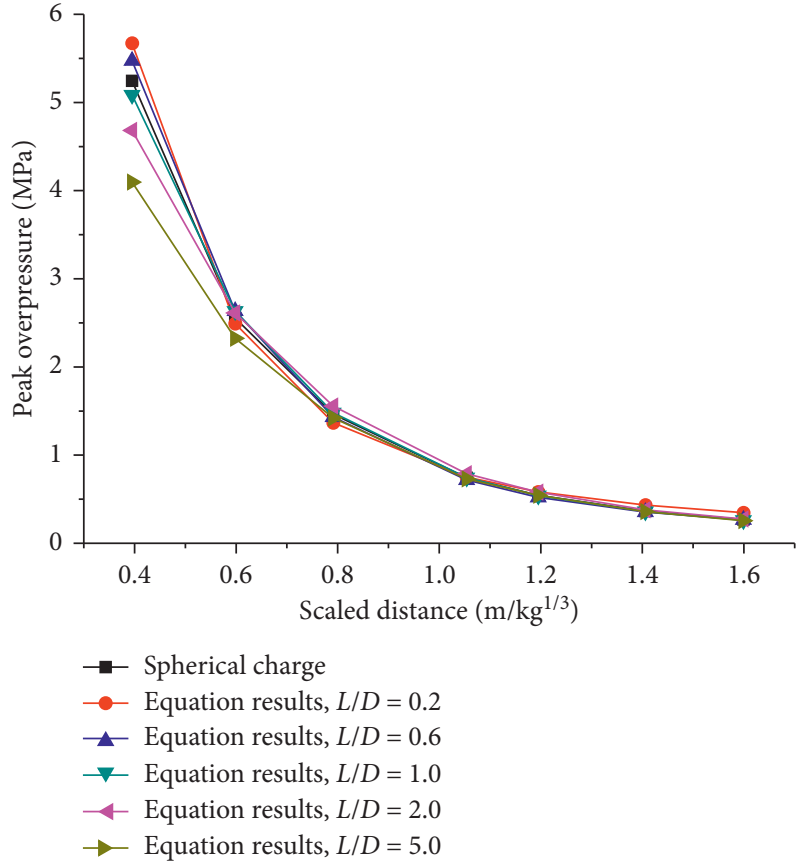

(a)

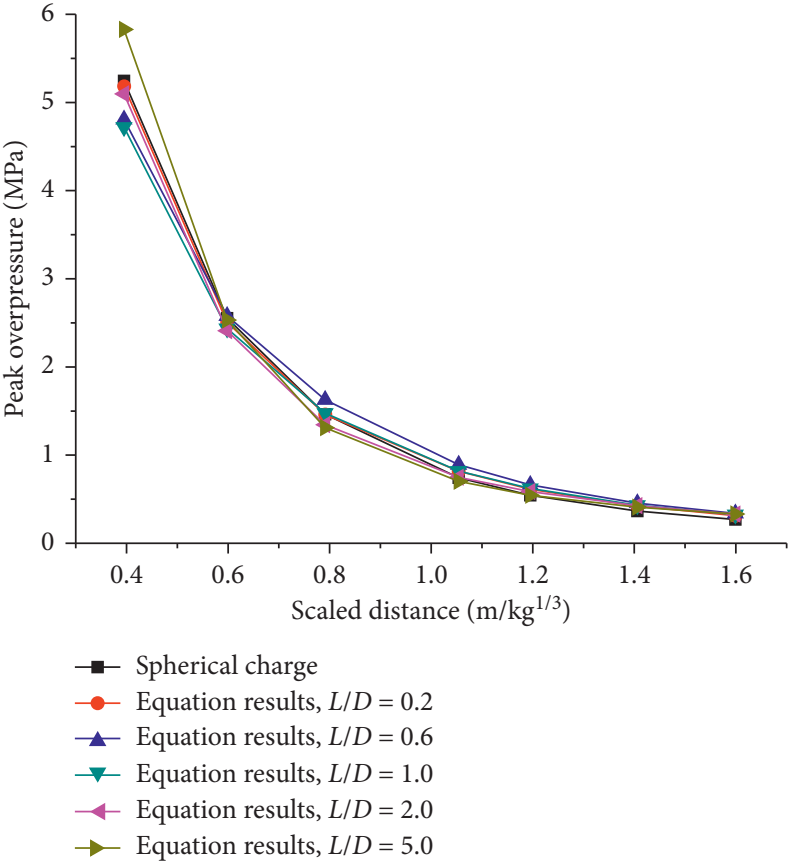

(b)

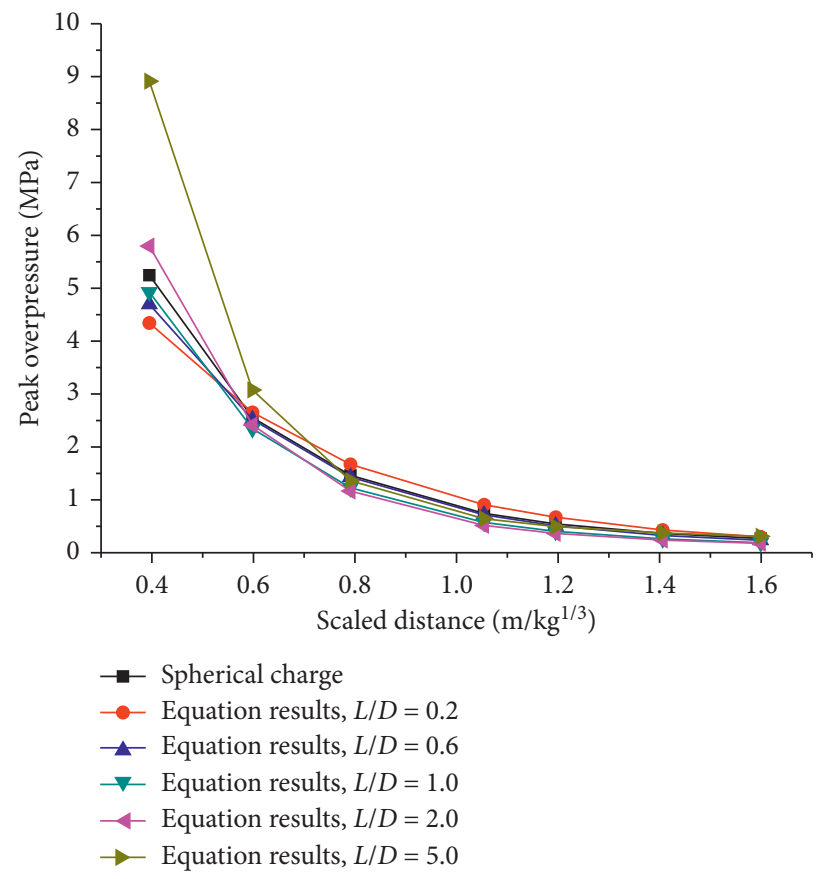

(c)

Figure 9: Comparison of peak overpressure between the spherical explosive and empirical results of the cylindrical explosives. (a) Radial direction. (b) $45^{\circ}$ direction. (c) Axial direction.

It can be concluded from the above test results that the shape of the explosive has a significant effect on the damage modes and spatial distribution characteristics of the RC slabs under air contact explosion. Besides, the aspect ratio of the explosive will straight decide the shape of concrete crater damage on the upper surface of the RC slab.

\section{Numerical Simulation of the RC Slabs under Cylindrical and Spherical Explosives}

4.1. Numerical Model. In the numerical simulation, a fully coupled Lagrangian-Eulerian method is used to model the dynamic response of the RC slab under contact spherical 


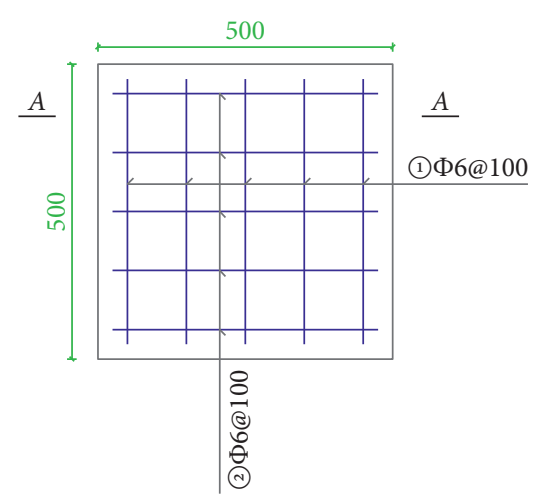

(a)

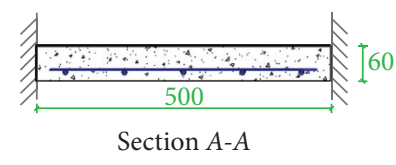

(b)

FIGURE 10: Geometry and reinforcement of the RC slab. Note: all dimensions are in millimeters.

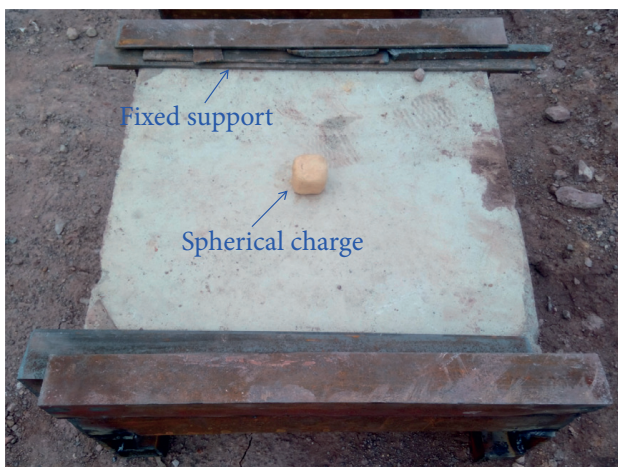

(a)

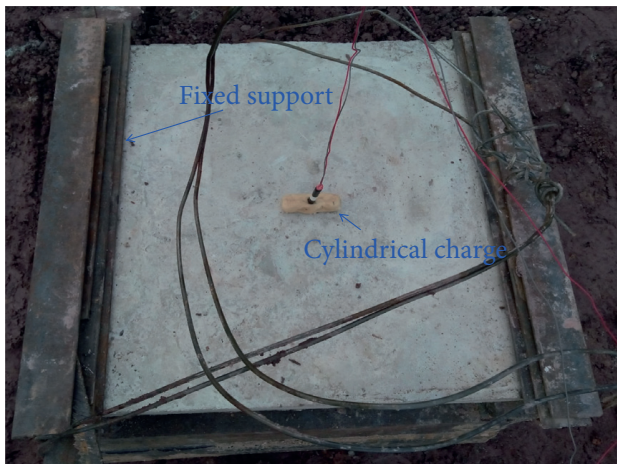

(b)

Figure 11: Air contact blast tests setup. (a) Spherical explosive. (b) Cylindrical explosive.

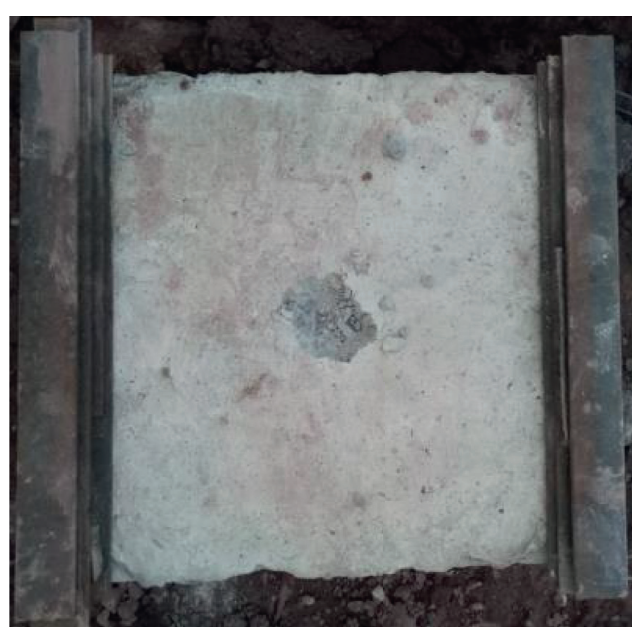

(a)

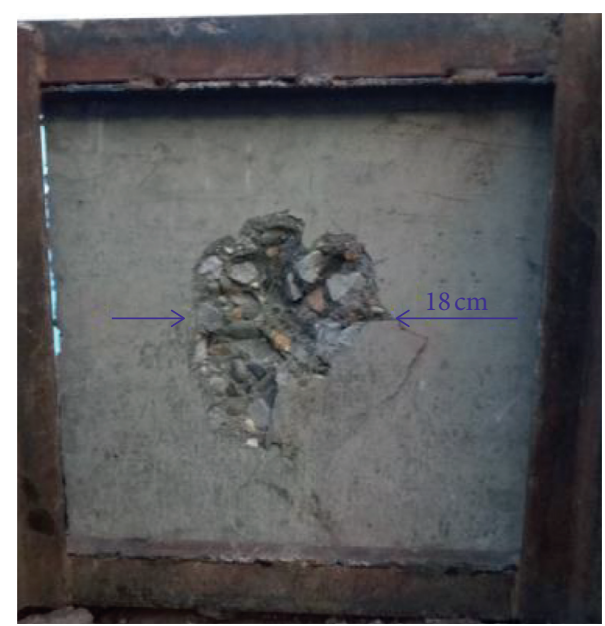

(b)

Figure 12: Test results of the spherical explosive. (a) Upper surface. (b) Bottom surface.

explosion load, as well as the cylindrical explosives. The structural configuration, charge weight, element size, and boundary of the model for cylindrical explosive are assumed the same as the model for spherical explosive. Hence, the geometry and numerical models of the RC slab under contact explosion are only shown with the spherical explosive, as shown in Figure 14. In the numerical model, concrete is described by the Lagrange grid, and concrete materials deform and move with the grid. The explosive and air are described by the Euler grid, in which the grid is fixed, 


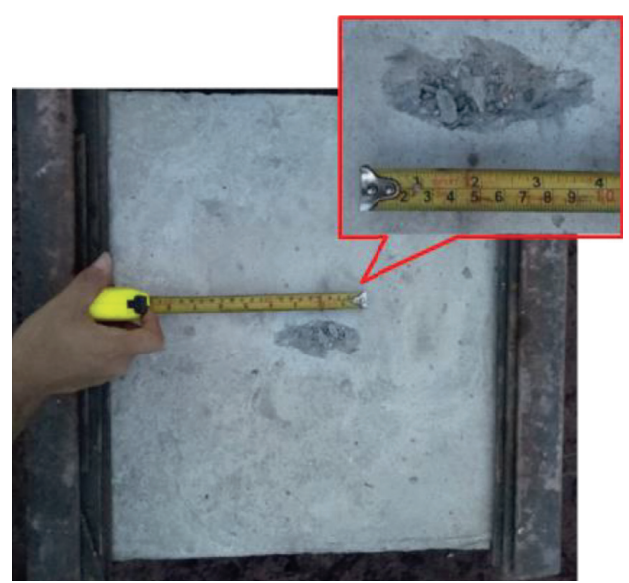

(a)

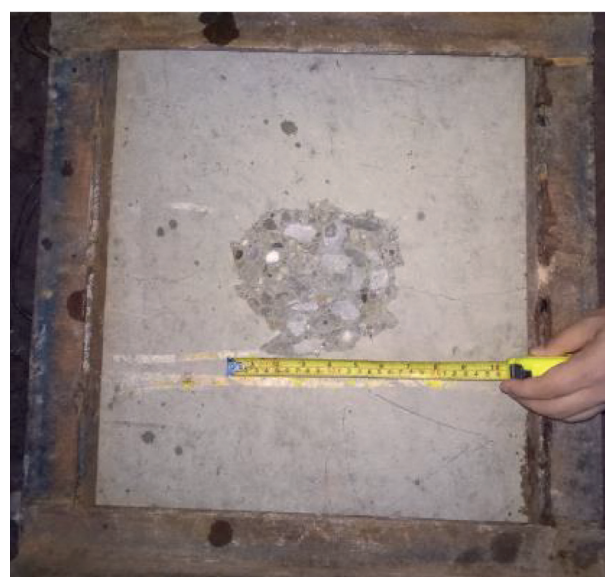

(b)

Figure 13: Test results of the cylindrical explosive. (a) Upper surface. (b) Bottom surface.

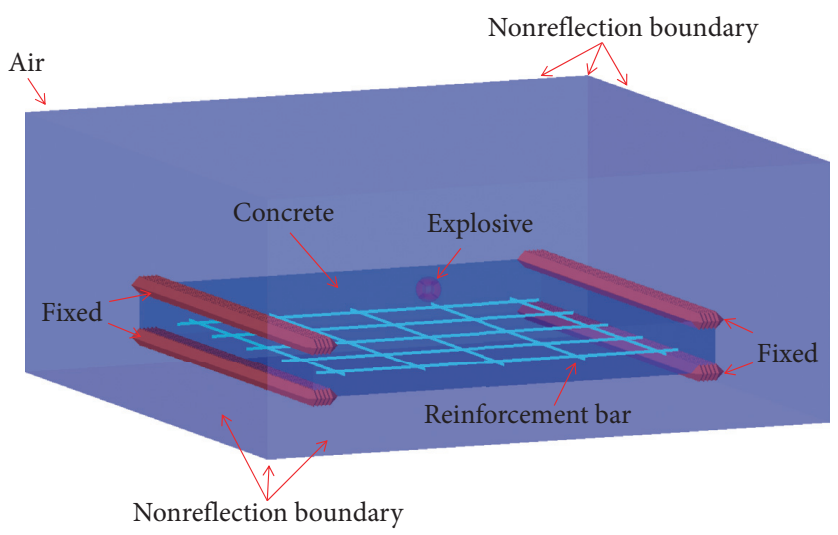

FIGURE 14: Geometry model of the RC slab subjected to air contact blast.

and the material could flow through the grid (Figure 14). The steel bars are described by the beam element and assumed to be perfectly bonded with the concrete Lagrange grid. This assumption is reasonable because there is not enough time for the activation of bond-slip between bars and concrete under contact blasting loads. Moreover, comparing with quasi-static loading, it is deemed that dynamic bond at failure is $70-100 \%$ higher [31].

As shown in Figure 14, the boundary condition of the air is set as a nonreflection boundary outflow. Moreover, upper and bottom supports are created in the supporting area of the RC slab, and all the displacements of the supports are fixed. After grid sensitivity analysis, the mesh size of $5 \mathrm{~mm}$ is used in the current numerical model for all of the materials, and the concrete slab zone contains 120000 elements. A spherical and five cylindrical charges are used; the $L / D$ ratios of the cylindrical charges are $0.2,0.6,1.0,2.0$, and 5.0, respectively, as shown in Figure 15.

4.2. Material Models for Concrete and Reinforcement Bar. The Riedel, Hiermaier, and Thoma (RHT) [32] model is widely used to model the dynamic response of brittle materials, such as concrete and rock [33-35]. The model can reflect the characteristics of the concrete material behavior at a high strain rate. And this model contains many features, such as strain hardening, pressure hardening, strain rate hardening, cumulative damage, and third invariant dependence for compressive and tensile meridians. The RHT model can be used in combination with the existing tensile crack softening algorithm. The influence of strain rate dependence is considered by expanding the failure surface in the stress space where the degree of expansion depends on the hydrostatic stresses; i.e., the dynamic increase effect is larger for tensile than compressive states of stress. The dependence of the third invariant takes into account the influence of the loading path on the yield surface. This model uses three strength surfaces (elastic limit surface, failure surface, and remaining strength surface) for the crushed material, and a cap often exists on the elastic strength surface (Figure 16). Hence, the RHT dynamic damage model is used to model the concrete material in this study.

The material constants $[28,36]$ adopted in this study are based on the typical data for concrete, where density $\rho=2.55 \mathrm{~g} / \mathrm{cm}^{3}$, shear modulus $G=16.7 \mathrm{GPa}$, compressive strength $f_{c}=39.5 \mathrm{MPa}$, tensile strength $f_{t}=8.2 \mathrm{MPa}$, the 


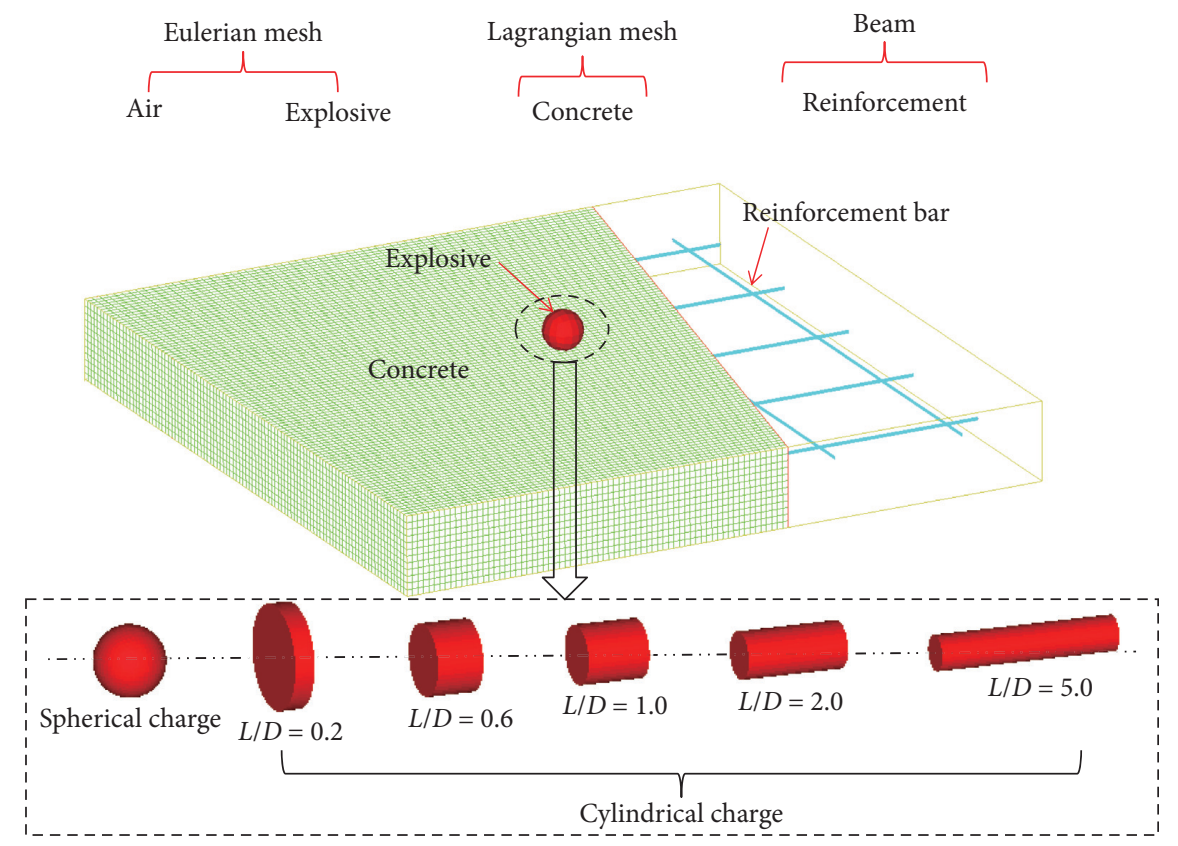

FIgURE 15: Finite element numerical model of the RC slab under contact blast.

failure strain is 0.001 , and failure surface constant $A=1.6$; failure surface exponent $N=0.61$; residual failure constant $B=0.7$; residual failure surface exponent $M=0.8$; damage constants $D_{1}$ and $D_{2}$, which are used to describe the effect strain to fracture as a function of pressure, are 0.015 and 1.0, respectively; minimum strain to reach failure $\varepsilon_{f}^{\min }=0.0008$. In order to simulate the large deformation of the postfailure area such as concrete spall damage and avoid premature corrosion of components, this study chooses the large principal strain (i.e., 2.0) recommended by the material library in AUTODYN as the corrosion criterion.

In the present study, the John-Cook model [37] is used to model the steel bars, which is widely used to model the strength behavior of materials under dynamic loads. Moreover, this model takes into account the strain rate effect on the material strength. The model defines the yield stress $Y$ as

$$
\sigma=\left[A+B \varepsilon_{p}^{n}\right]\left[1+C \operatorname{In} \frac{\dot{\varepsilon}_{p}}{\dot{\varepsilon}_{0}}\right]\left[1-T_{H}^{m}\right],
$$

where $\varepsilon_{p}$ is the effective plastic strain; $\dot{\varepsilon}_{p}^{*}=\dot{\varepsilon} / \dot{\varepsilon}_{0}$ is the normalized effective plastic strain rate for $\dot{\varepsilon}_{0}=1 \mathrm{~S}^{-1}$; and $T_{H}=\left(T-T_{\text {room }}\right) /\left(T_{\text {melt }}-T_{\text {room }}\right)$, where $T_{\text {room }}$ is the room temperature and $T_{\text {melt }}$ is the melting temperature; and $A, B$, $C, n$, and $m$ are material constants. The constant $A$ is the basic yield stress at low strain, whereas $B$ and $n$ represent the effect of strain hardening. The second and third brackets in (3) represent the effects of strain rate and temperature, respectively. The steel bars material constants adopted in this study are based on steel 4340 of AUTODYN [28]; the material parameters are as follows: reference density $\rho=7.83 \mathrm{~g} / \mathrm{cm}^{3}$, shear modulus $G=81.8 \mathrm{GPa}$, bulk modulus $K=159 \mathrm{GPa}$, reference room temperature $T_{\text {room }}=300 \mathrm{~K}$, melting temperature $T_{\text {melt }}=1793 \mathrm{~K}$, and the material constants $A=792 \mathrm{MPa}, B=510 \mathrm{MPa}, C=0.014, n=0.26$, and $m=1.03$.
4.3. Validation of the Numerical Model. The final numerical damage profiles of the RC slabs under $20 \mathrm{~g}$ rock emulsion explosive are shown in Figures 17 and 18. The contour value 0-1 means the concrete material ranges from undamaged to fully damaged. Contact explosion, unlike close-in explosion or far explosion, produces extremely high shock wave pressure. Hence, it is difficult to obtain quantitative data (such as pressure and velocity) during the experiment because the equipment installed on the test slab can be easily destroyed and separate from the test slab under such a high shock wave. Consequently, many researchers have used the damage modes to verify the accuracy and reliability of the numerical model in comparison with the experimental results $[38,39]$. It should be noted that since the deformation and strain data of the test slab are not obtained, only the failure characteristics and failure dimension are compared between the test slabs and the numerical results in this paper.

The numerical results (Figures 17 (a) and 18(a)) show that there is crater damage on the upper surface of the slabs; the shapes of the crater are consistent with the explosion test results, as shown in Figures 12(a) and 13(a). On the bottom center surface of the RC slabs, there is spall damage due to the low resistance of concrete material to tension; see Figures 17(b) and 18(b). Similarly, Figures 12(b) and 13(b) show the same spall damage on the bottom surface of the RC slabs in the experimental tests. However, in the numerical simulation, the damaged area of the slab upper surface is larger than the experimental results. This is because the position of the gravity center of the charge in the test is lower than the position of the designed center of gravity due to gravity. As a result, the explosive is closer to the upper surface of the RC slab in the experiment test than in the numerical simulation. Another reason is the boundary condition in the field tests is relatively "softer" than that during the numerical simulation. For the second reason, the 


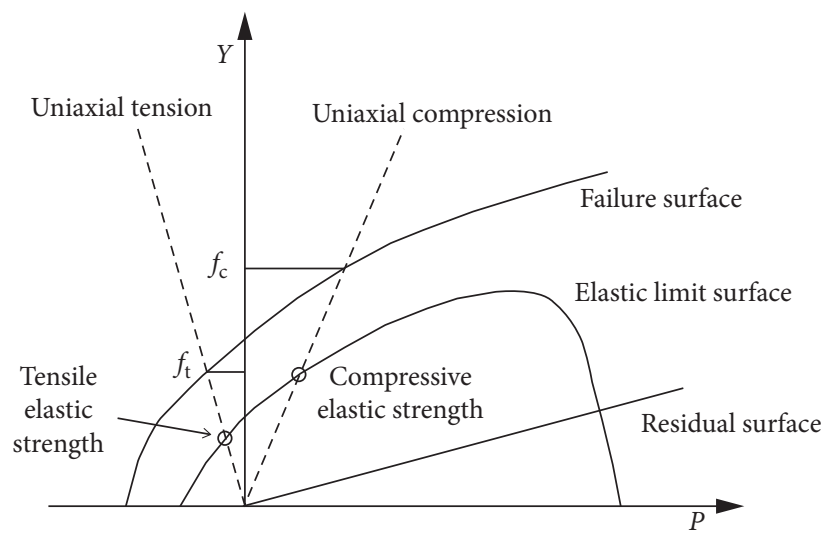

FiguRE 16: Maximum strength, yield strength, and residual strength surfaces.

support locations of the RC slabs suffer higher damage in the numerical simulation than the experiment results; see Figures 17 and 18.

By comparing the current results with the blast tests, the differences are insignificant; it may be concluded that the numerical results show a favorable agreement with the experimental results in terms of crater and spall damage, which means the computed results are credible.

\subsection{Influence of the L/D Ratio of the Cylindrical Explosives on} the Damage Features of the RC Slabs. To study the influence of the $L / D$ ratio on the damage features of $\mathrm{RC}$ slabs under cylindrical explosives, simulations are conducted again with $L / D$ equal to $0.2,0.6,1.0,2.0$, and 5.0 .

Figure 19 shows the damage process of the RC slabs under contact spherical and cylindrical explosives with different aspect ratios. It can be seen from Figure 19(a) that larger circular crater damage is present on the upper surface of the RC slab under spherical explosive compared with cylindrical explosives. Under the cylindrical explosives, the shapes of the crater damage vary depending on the $L / D$ ratio, as shown in Figures 19(b) $\sim 19$ (f). For $L / D=1.0$, the shape of the crater damage approached a circle (Figure 19(d)), but when $L / D$ increases to 5.0 , the shape of the crater damage is rectangular (Figure 19(f)). However, as shown in Figure 19, the shapes of the spall damage on the slab bottom surface are the same circular under the spherical charge as well as the cylindrical explosives with different aspect ratio.

It is well known that spall damage and fragmentation may bring a significant threat to the equipment and personnel back side of the RC structure. Therefore investigation upon spall damage on the bottom surface of the RC slabs is important and essential. The comparisons between the spall damage area (fully damaged) under spherical and cylindrical explosives with different $L / D$ ratios are shown in Figure 20. For the cylindrical charge, the spall damaged area becomes larger as the $L / D$ ratio is increased, as shown in Figure 20. This is because the center of gravity of the charge is closer to the slabs as the $L / D$ ratio increased. Moreover, as the aspect ratio increases, more blasting energy is concentrated in the radial direction. The spall damage area induced by cylindrical charge with $L / D=5.0$ is
45\% larger than that caused by the cylindrical charge with an $L / D$ ratio equal to 0.2 . For the $L / D<2.0$, the cylindrical charges cause smaller spall damage than the spherical charge with the same charge mass. However, when the aspect ratio of the cylindrical charge increased to 5.0, the cylindrical charge will induce $13 \%$ larger spall damage than the spherical charge.

To monitor the distribution of the stress wave in the RC slabs, nine target points are arranged in the RC slabs to record the peak pressure, as well as the velocity. All of the targets are located in a line that is perpendicular to the axis of the cylindrical explosives and point \#5 is right below the explosive center.

As can be seen from Figure 21, the peak pressures at the targets become larger as the $L / D$ ratio is increased. When the $L / D$ ratio increased to 5.0 , the peak pressures from cylindrical explosives are larger than those from the spherical explosive, except for point 5\#. The peak pressures at point \#5 from spherical explosive are much higher than these from the cylindrical explosives with different $L / D$ ratios, as shown in Figure 21. For $L / D=0.2$, the peak pressure of target 5\# from the spherical explosive is around double that of the cylindrical explosive. This is because point \#5 is right below the explosive center. The peak of velocity recorded at the targets showed the same changing rule, as shown in Figure 22. However, the difference of the peak velocity between the spherical and cylindrical explosives decreases with increasing scaled distance.

From all the research above, it can be found that the RC slab suffered the greatest damage under the cylindrical charge with $L / D=5.0$. Hence, the accumulated damage processes of the RC slabs under spherical and cylindrical explosives with $L / D$ ratio equal to 5.0 are compared, as shown in Figures 23 and 24.

It can be seen from Figures 23 and 24 that the crater and spall damage quickly expand in the first $0.20 \mathrm{~ms}$. The crater damage is initially observed to occur on the contact region of the explosive and the slab due to the strike of direct blasting pressure and detonation products. Therefore, the shapes of the crater damage are kept the same as the explosive shape, as shown in Figures 23(a) and 24(a). At $t=0.02 \mathrm{~ms}$, the bottom surface suffers the spall damage due to reflective tensile stress wave (Figures 23(b) and 24(b)). However, the 


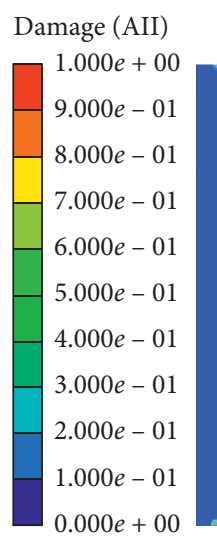

$0.000 e+00$

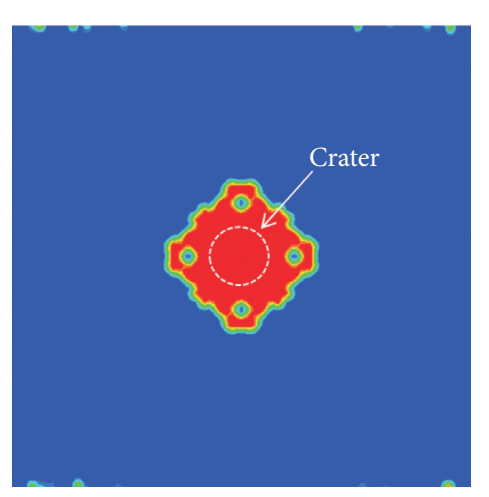

(a)
Damage (AII)
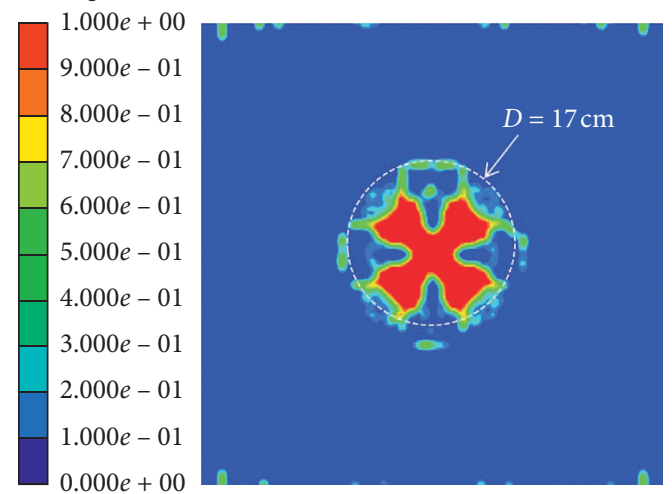

(b)

FiguRE 17: Simulation results under spherical explosive. (a) Upper surface. (b) Bottom surface.

Damage (AII)
\begin{tabular}{|}
$1.000 e+00$ \\
$9.000 e-01$ \\
$8.000 e-01$ \\
$7.000 e-01$ \\
$6.000 e-01$ \\
$5.000 e-01$ \\
$4.000 e-01$ \\
$3.000 e-01$ \\
$2.000 e-01$ \\
$1.000 e-01$ \\
$0.000 e+00$
\end{tabular}

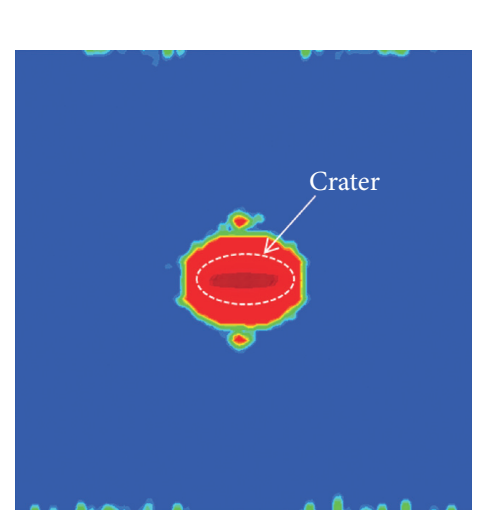

(a)

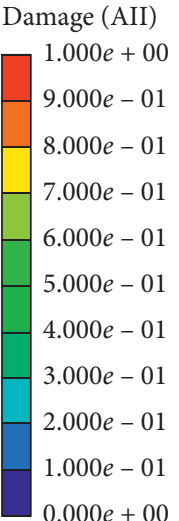

$0.000 e+00$

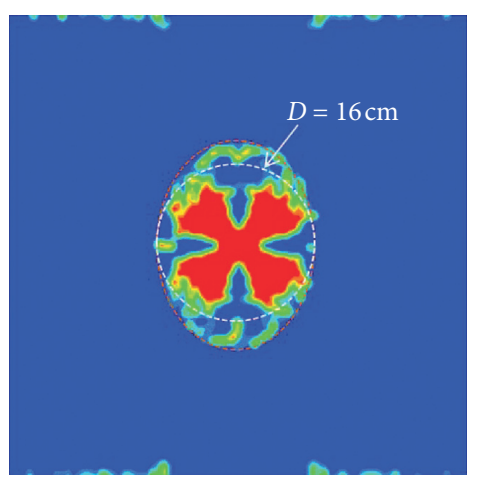

(b)

FIGURE 18: Simulation results under cylindrical explosive. (a) Upper surface. (b) Bottom surface.

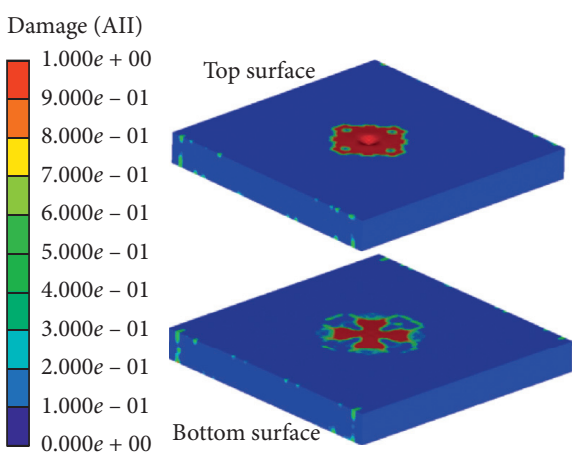

(a)

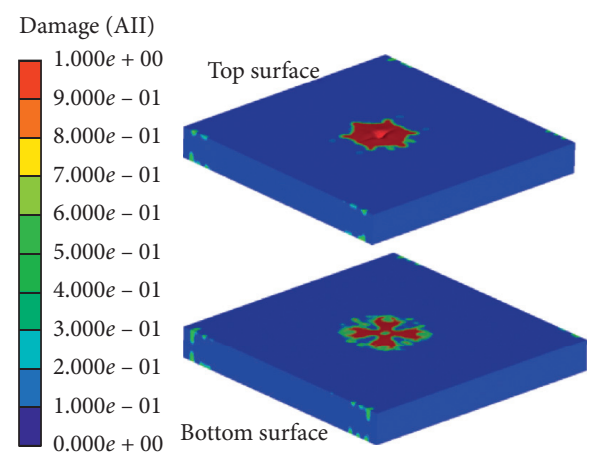

(b)

FIgURE 19: Continued. 


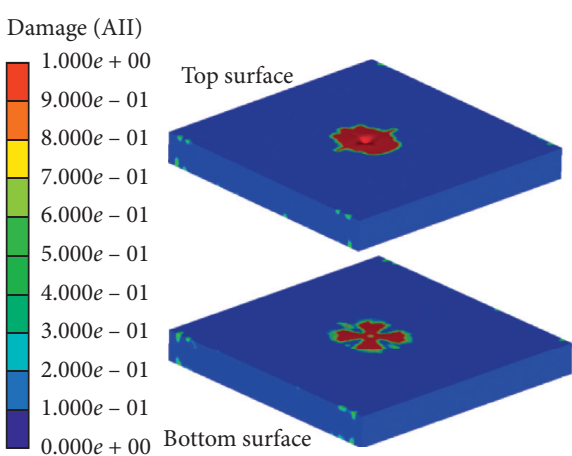

(c)

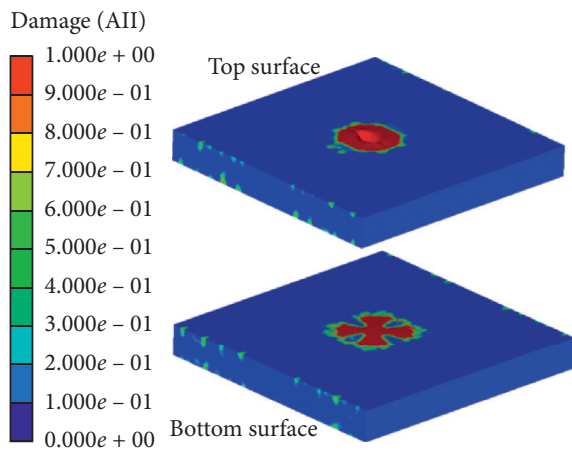

(e)

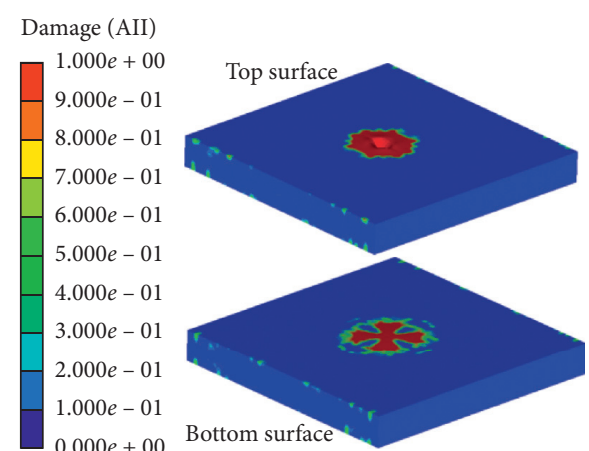

(d)

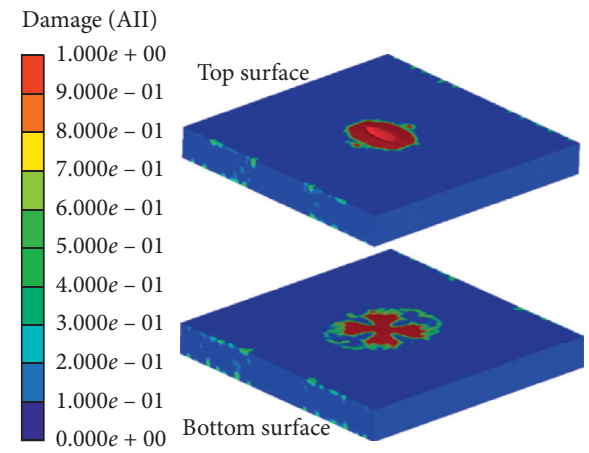

(f)

Figure 19: Damage features of the RC slabs under spherical and cylindrical explosives. (a) Spherical explosive. (b) Cylindrical explosive with $L / D=0.2$. (c) Cylindrical explosive with $L / D=0.6$. (d) Cylindrical explosive with $L / D=1.0$. (e) Cylindrical explosive with $L / D=2.0$. (f) Cylindrical explosive with $L / D=5.0$.

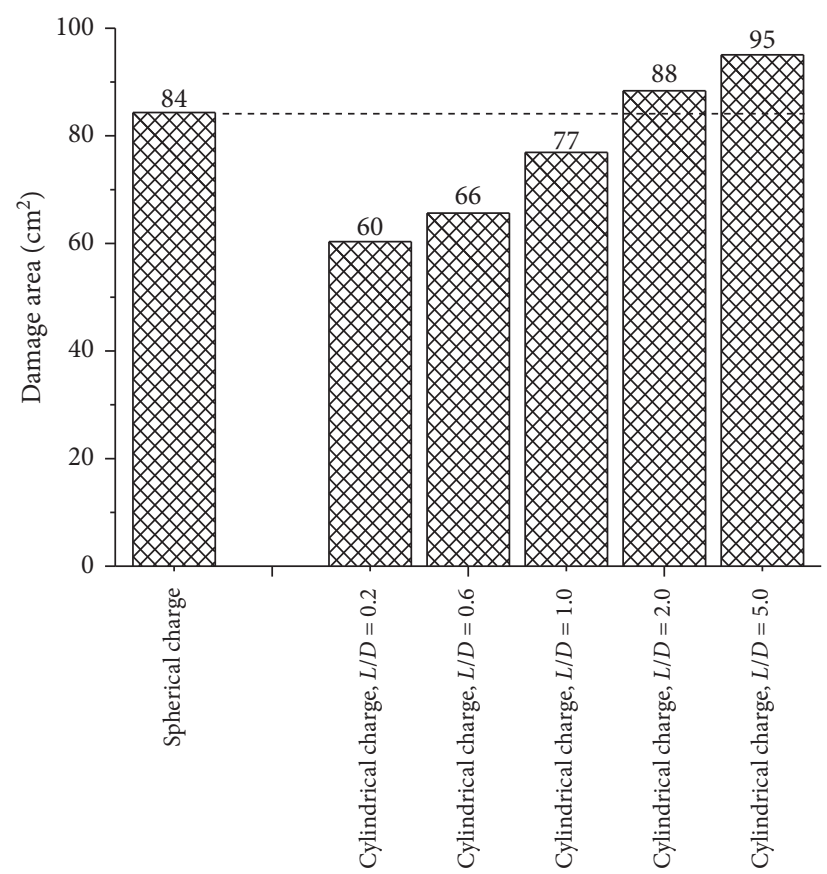

Figure 20: Spall damage areas at bottom surface of the slabs from the spherical and cylindrical explosives.

spall failure shapes of the RC slabs under spherical and cylindrical explosives are the same circle shape (Figures 23(d) and 24(d)). This is because there are interactions between the incident compressive stress and reflective tensile stress (i.e., on the upper surface of the slab) before the stress wave reaches the bottom surface of the slab. 


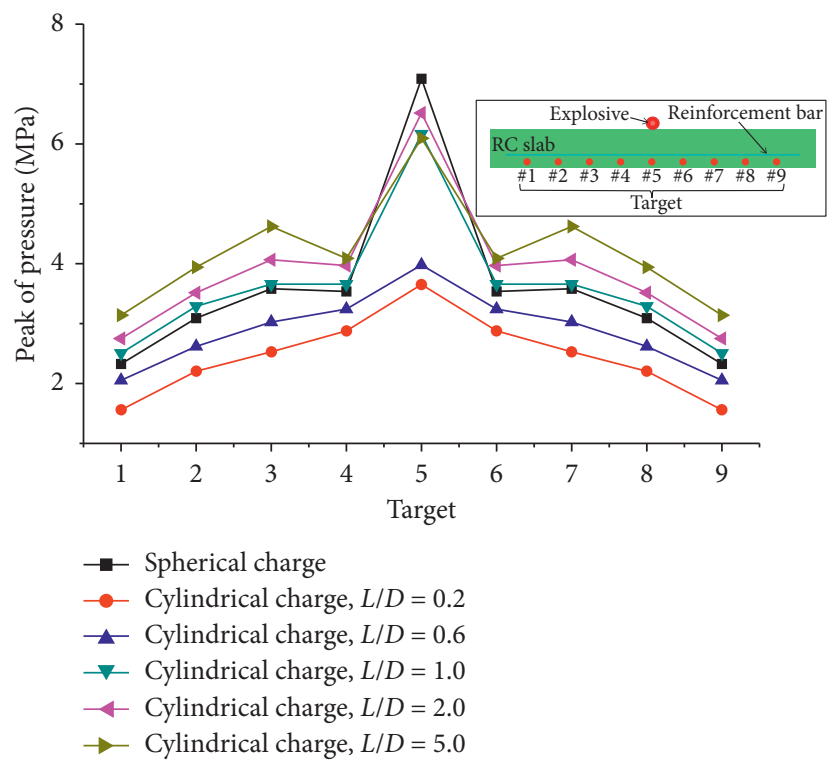

FIGURE 21: Comparison of peak pressures at targets from the spherical and cylindrical explosives.

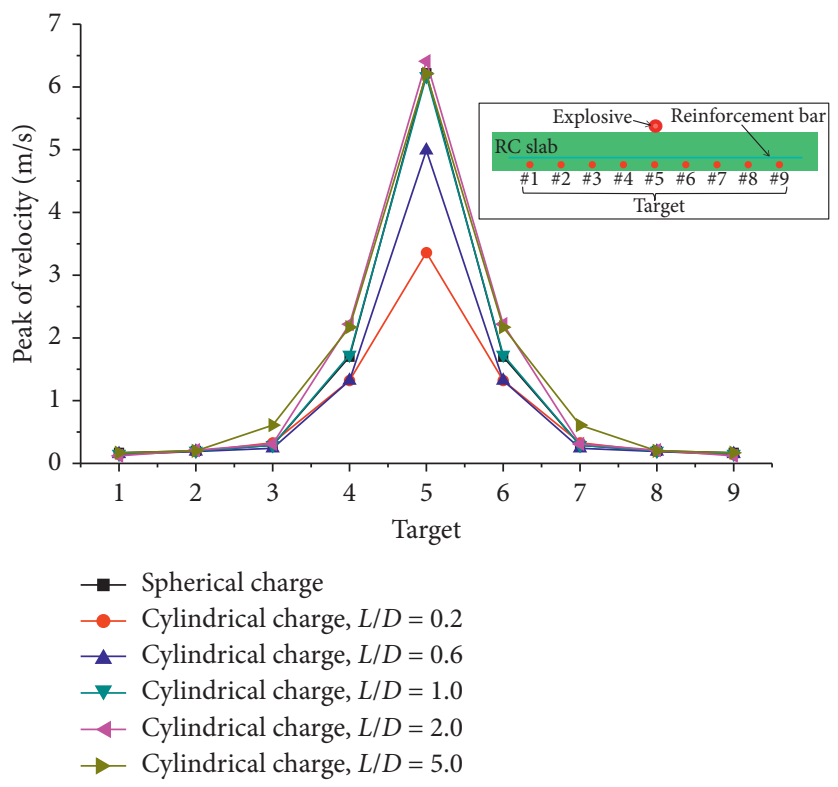

Figure 22: Comparison of peak velocities at targets from the spherical and cylindrical explosives.

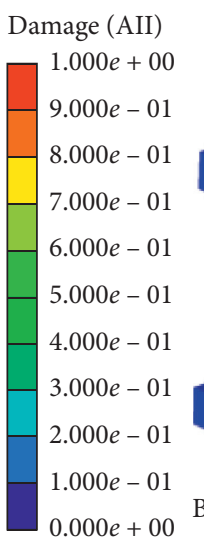

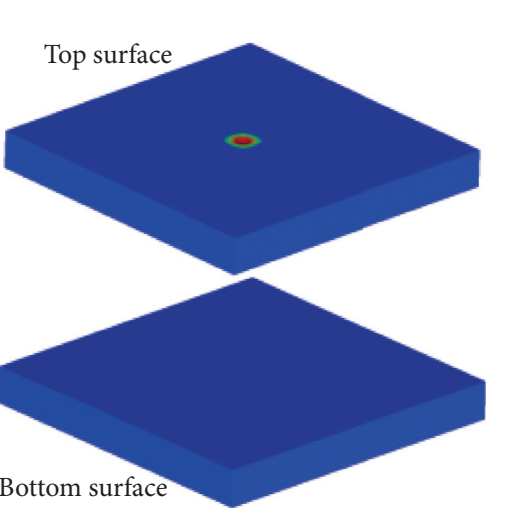

(a)

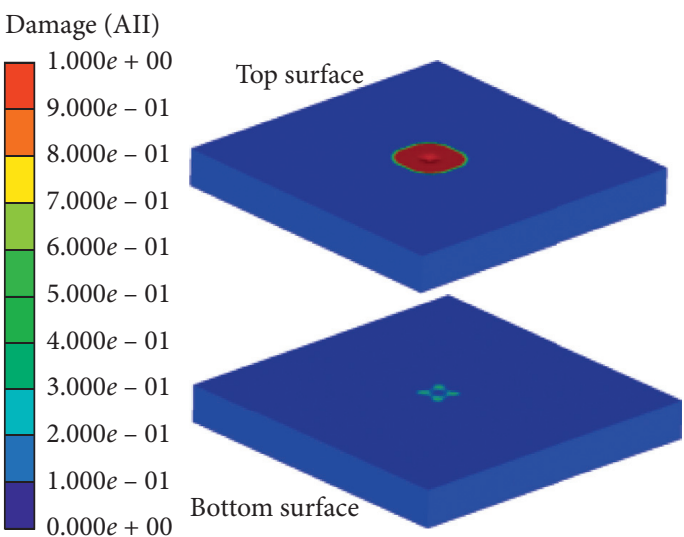

(b)

FIgURe 23: Continued. 


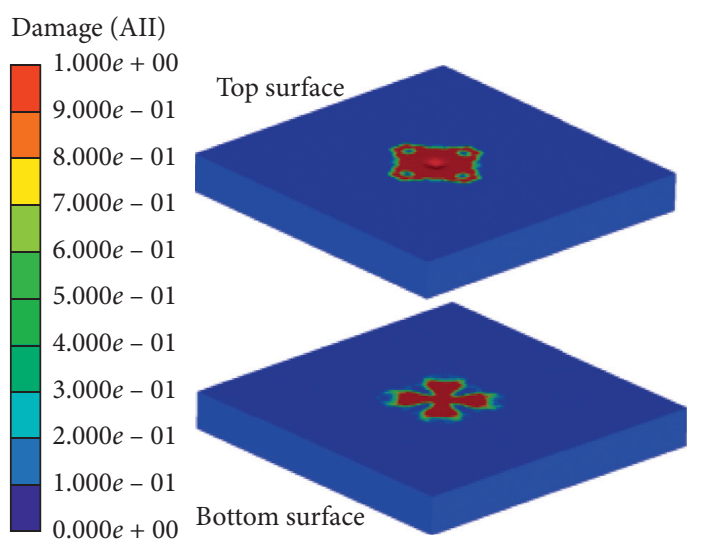

(c)

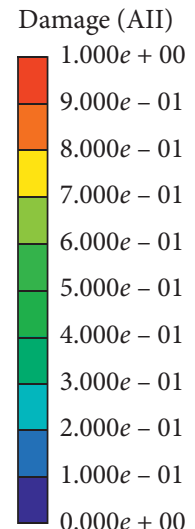

$0.000 e+00$

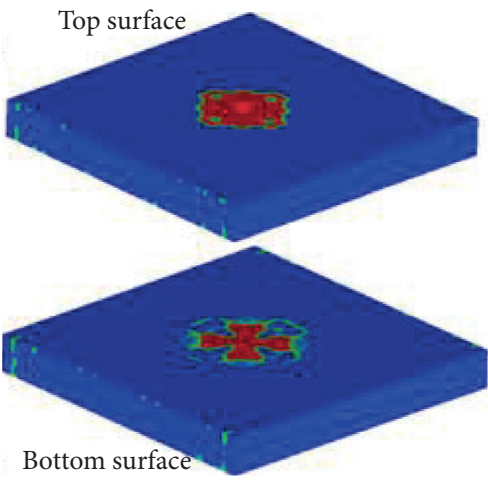

(d)

Figure 23: The damage processes of the RC slab under spherical explosive. (a) $t=0.01 \mathrm{~ms}$. (b) $t=0.02 \mathrm{~ms}$. (c) $t=0.05 \mathrm{~ms}$. (d) $t=0.20 \mathrm{~ms}$.
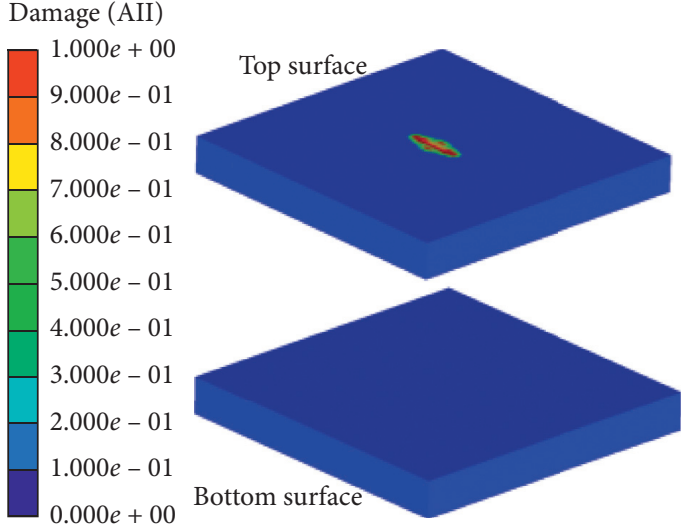

(a)

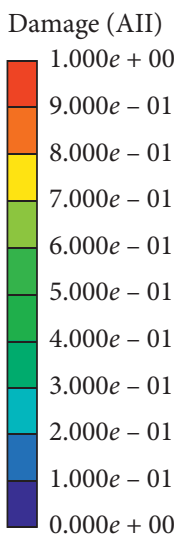

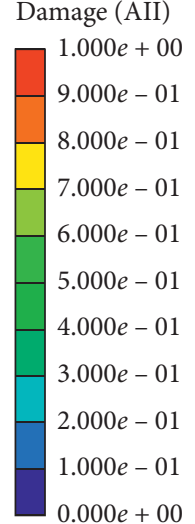

$0.000 e+00$

Damage (AII)

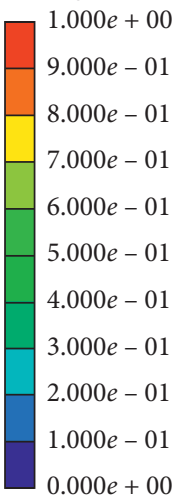

$0.000 e+00$

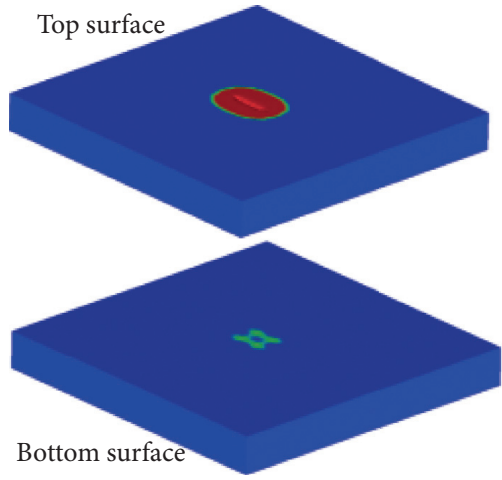

(b)

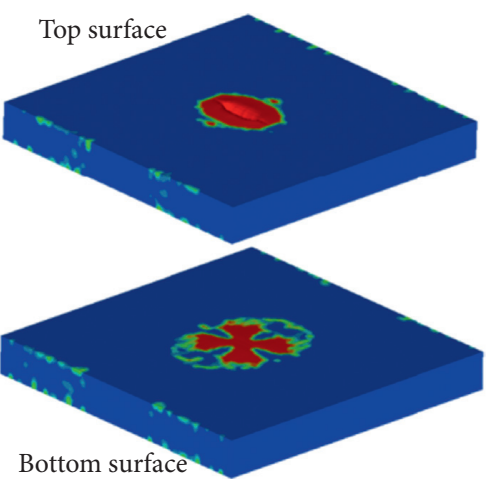

(d)

Figure 24: The damage processes of the RC slab under cylindrical explosive. (a) $t=0.01 \mathrm{~ms}$. (b) $t=0.02 \mathrm{~ms}$. (c) $t=0.05 \mathrm{~ms}$. (d) $t=0.20 \mathrm{~ms}$.

\section{Conclusions}

The objective of this paper is to investigate the effect of the $L / D$ ratio on the shock wave propagation characteristics and damage features of RC slabs under air contact cylindrical explosive. For this purpose, a two-dimensional numerical model is used to compare the peak overpressure from spherical explosives with that from cylindrical explosives with different aspect ratios. Subsequently, two RC slabs are tested under spherical and cylindrical explosives, respectively. Moreover, the fully coupled Eulerian-Lagrangian method is verified through comparing with the test results. 
Then, the simulation failure modes of the RC slabs subjected to spherical and cylindrical explosives with different $L / D$ ratios are compared and discussed. The following conclusions are drawn from this investigation:

(1) The $L / D$ ratio of the cylindrical explosive has a significant effect on the shock wave propagation characteristics and peak overpressure value. As the aspect ratio increases, more blasting energy is concentrated in the radial direction. The peak overpressure from cylindrical explosives increases with the increase of $L / D$ ratio in the radial direction but decreases with the increase of $L / D$ ratio in the axial direction. The difference of the peak overpressure between the spherical and cylindrical explosives with different $L / D$ ratios decreases with increasing scaled distance. For close-in explosion, an equation is produced for predicting the peak overpressure from a cylindrical explosive based on the numerical results.

(2) In the contact explosion tests, the RC slabs suffer the same crater and spall damage modes subjected to spherical and cylindrical explosives. The shape of the upper surface crater damage is kept the same as the explosive shape under contact blasting load. Comparing with cylindrical explosive with $L / D=4.0$, the $\mathrm{RC}$ slab suffers deeper spall damage on the bottom surface under spherical explosive.

(3) The numerical method can predict effectively the damage profiles of RC slabs under contact explosion. The spall damaged area becomes larger as the $L / D$ ratio is increased. For the $L / D$ ratio increase to a certain value, the cylindrical explosive will induce larger spall damage than the spherical explosive. Hence, the effect of the cylindrical explosive should be considered in the antiknock design of the RC structure.

\section{Data Availability}

Data are included in the tables and figures of the paper.

\section{Conflicts of Interest}

The authors declare that they have no conflicts of interest.

\section{Acknowledgments}

The authors gratefully appreciate the supports from the National Natural Science Foundation of China (52009126), Key Scientific Research Projects of Colleges and Universities in Henan Province (21A570006), the Outstanding Young Talent Research Fund of Zhengzhou University (1621323001), and the Educational Commission of Hubei Province of China (T2020005).

\section{References}

[1] C. Knock and N. Davies, "Blast waves from cylindrical charges," Shock Waves, vol. 23, no. 4, pp. 337-343, 2013.
[2] UFC-3-340-02, Unified Facilities Criteria UFC DOD Structures to Resist the Effects of Accidental Explosions, US Department of Defense, Arlington, VA, USA, 2008.

[3] TM5-1300, Structures to Resist the Effects of Accidental Explosions, US Department of the Army, Navy and Air Force Technical Manual, Arlington, VA, USA, 1990.

[4] ASCE/SEI 59-11, Blast Protection of Buildings, American Society of Civil Engineers, Reston, VA, USA, 2011.

[5] M. M. Ismail and S. G. Murray, "Study of the blast waves from the explosion of nonspherical charges," Propellants, Explosives, Pyrotechnics, vol. 18, no. 3, pp. 132-138, 1993.

[6] J. Wisotski and W. H. Snyer, Characteristics of Blast Waves Obtained from Cylindrical High Explosive Charges, University of Denver, Denver, CO, USA, 1965.

[7] E. D. Esparza, Spherical Equivalency of Cylindrical Charges in Free-Air, Southwest Research Institute, San Antonio, TX, USA, 1992.

[8] P. Sherkar, J. Shin, A. Whittaker, and A. Aref, "Influence of charge shape and point of detonation on blast-resistant design," Journal of Structural Engineering, vol. 142, no. 2, Article ID 04015109, 2016.

[9] C. Wu, G. Fattori, A. Whittaker, and D. J. Oehlers, "Investigation of air-blast effects from spherical-and cylindrical-shaped charges," International Journal of Protective Structures, vol. 1, no. 3, pp. 345-362, 2010.

[10] H. D. Zimmerman, C. T. Nguyen, and P. A. Hookham, "Investigation of spherical vs cylindrical charge shape effects on peak free air overpressure and impulse," in Proceedings of 9th International Symposium on Interaction of the Effects of Munitions with Structures, Berlin, Germany, May 1999.

[11] R. G. Stoner and W. Bleakney, "The attenuation of spherical shock waves in air," Journal of Applied Physics, vol. 19, no. 7, pp. 670-678, 1948.

[12] C. Knock and N. Davies, "Predicting the peak pressure from the curved surface of detonating cylindrical charges," Propellants, Explosives, Pyrotechnics, vol. 36, no. 3, pp. 203-209, 2011.

[13] M. N. Plooster, Blast Effects from Cylindrical Explosive Charges: Experimental Measurements, Denver Research Institute, Denver, CO, USA, 1982.

[14] F. Pechoux, B. Simeons, and M. H. Lefebrve, "TNT-equivalent and explosive charge characteristics," in Proceedings of the 10eme Congres International De Pyrotechnic Du Groupe De Travail De Pyrotechnie, pp. 592-597, Reims, France, 2011.

[15] USAF, JMEM the Joint Munitions Effectiveness Manual, USAF-61A1-3-7; NAVY NAVAIR 00-130-ASR-2-1; USMC FMFM 5-21; ARMY FM 101-51-3, Washington, DC, USA, 1989.

[16] M. Plooster, Blast Front Pressure from Cylindrical Charges of High Explosive, Denver Research Institute, Denver, CO, USA, 1977.

[17] C. Wu, D. J. Oehlers, M. Rebentrost, J. Leach, and A. S. Whittaker, "Blast testing of ultra-high performance fibre and FRP-retrofitted concrete slabs," Engineering Structures, vol. 31, no. 9, pp. 2060-2069, 2009.

[18] K. Ohkubo, M. Beppu, T. Ohno, and K. Satoh, "Experimental study on the effectiveness of fiber sheet reinforcement on the explosive-resistant performance of concrete plates," International Journal of Impact Engineering, vol. 35, no. 12, pp. 1702-1708, 2008.

[19] M. Beppu, T. Ohno, K. Ohkubo, B. Li, and K. Satoh, "Contact explosion resistance of concrete plates externally strengthened with FRP laminates," International Journal of Protective Structures, vol. 1, no. 2, pp. 257-270, 2010. 
[20] Y. Liu, J. Yan, and F. Huang, "Behavior of reinforced concrete beams and columns subjected to blast loading," Defence Technology, vol. 14, no. 5, pp. 200-209, 2018.

[21] J. Li, C. Wu, H. Hao, and Y. Su, "Experimental and numerical study on steel wire mesh reinforced concrete slab under contact explosion," Materials \& Design, vol. 116, pp. 77-91, 2017.

[22] J. Li, C. Wu, H. Hao, Z. Wang, and Y. Su, "Experimental investigation of ultra-high performance concrete slabs under contact explosions," International Journal of Impact Engineering, vol. 93, pp. 62-75, 2016.

[23] M. Ohtsu, F. A. K. M. Uddin, W. Tong, and K. Murakami, "Dynamics of spall failure in fiber reinforced concrete due to blasting," Construction and Building Materials, vol. 21, no. 3, pp. 511-518, 2007.

[24] T. Zhuang, M. Wang, J. Wu, C. Y. Yang, T. Zhang, and C. Gao, "Experimental investigation on dynamic response and damage models of circular RC columns subjected to underwater explosions-sciencedirect," Defence Technology, vol. 16, no. 4, pp. 856-875, 2020.

[25] S. D. Adhikary, L. R. Chandra, A. Christian, and K. C. Gary Ong, "Influence of cylindrical charge orientation on the blast response of high strength concrete panels," Engineering Structures, vol. 149, pp. 35-49, 2017.

[26] L. Yuan, S. Gong, and W. Jin, "Spallation mechanism of RC slabs under contact detonation," Transactions of Tianjin University, vol. 14, no. 6, p. 464, 2008.

[27] G. Wang and S. Zhang, "Damage prediction of concrete gravity dams subjected to underwater explosion shock loading," Engineering Failure Analysis, vol. 39, pp. 72-91, 2014.

[28] Autodyn, Theory Manual, Century Dynamics, Horsham, UK, 2006.

[29] J. A. Sanchidrián, R. Castedo, L. M. López, P. Segarra, and A. P. Santos, "Determination of the JWL constants for ANFO and emulsion explosives from cylinder test data," Central European journal of energetic materials, vol. 12, no. 2, pp. 177-194, 2015.

[30] G. F. Kinney and K. J. Graham, Explosive Shocks in Air, Springer-Verlag, New York, NY, USA, 1985.

[31] J. H. Weathersby, Investigation of Bond Slip between concrete and Steel Reinforcement under Dynamic Loading Conditions, Louisiana State University, Baton Rouge, LA, USA, 2003.

[32] W. Riedel, K. Thoma, and S. Hiermaier, "Numerical analysis using a new macroscopic concrete model for hydrocodes," in Proceedings of the 9th International Symposium on Interaction of effects of Munitions with Structures, pp. 315-322, Berlin, Germany, January 1999.

[33] X. Cai, Z. Zhou, H. Zang, and Z. Song, "Water saturation effects on dynamic behavior and microstructure damage of sandstone: phenomena and mechanisms," Engineering Geology, vol. 276, Article ID 105760, 2020.

[34] X. Cai, Z. Zhou, and X. Du, "Water-induced variations in dynamic behavior and failure characteristics of sandstone subjected to simulated geo-stress," International Journal of Rock Mechanics and Mining Sciences, vol. 130, Article ID 104339, 2020

[35] X. Cai, Z. Zhou, L. Tan, H. Zhang, and Z. Song, "Fracture behavior and damage mechanisms of sandstone subjected to wetting-drying cycles," Engineering Fracture Mechanics, vol. 234, Article ID 107109, 2020.

[36] Z. Tu and Y. Lu, "Evaluation of typical concrete material models used in hydrocodes for high dynamic response simulations," International Journal of Impact Engineering, vol. 36, no. 1, pp. 132-146, 2009.

[37] W. H. Johnson and G. R. Cook, "A constitutive model and data for metals subjected to large strains, high strain rates and high temperatures," in Proceedings of the 7th International Symposium on Ballistics, vol. 21, no. 1, pp. 541-547, The Hague, Netherland, April 1983.

[38] R. Castedo, P. Segarra, A. Alañon, L. M. Lopez, A. P. Santos, and J. A. Sanchidrian, "Air blast resistance of full-scale slabs with different compositions: numerical modeling and field validation," International Journal of Impact Engineering, vol. 86, pp. 145-156, 2015.

[39] B. Li, F. Wang, H. Fang, K. Yang, X. Zhang, and Y. Ji, "Experimental and numerical study on polymer grouting pretreatment technology in void and corroded concrete pipes," Tunnelling and Underground Space Technology, vol. 113, Article ID 103842, 2021. 